\title{
Tuft cell-produced cysteinyl leukotrienes and IL-25 synergistically initiate lung type 2 inflammation
}

Saltanat Ualiyeva ${ }^{1 \#}$, Evan Lemire ${ }^{2 \#}$, Evelyn C. Aviles ${ }^{3}$, Amelia A. Boyd ${ }^{1}$, Caitlin Wong ${ }^{1}$, Juying Lai $^{1}$, Tao Liu ${ }^{1}$, Ichiro Matsumoto ${ }^{4}$, Nora A. Barrett ${ }^{1}$, Joshua A. Boyce ${ }^{1}$, Adam L. Haber ${ }^{2}$, and Lora G. Bankova ${ }^{1 *}$

${ }^{1}$ Division of Allergy and Clinical Immunology, Jeff and Penny Vinik Center for Allergic

Disease Research, Brigham \& Women's Hospital and Department of Medicine, Harvard Medical School, Boston, MA.

${ }^{2}$ Department of Environmental Health, Harvard School of Public Health, Boston, MA.

${ }^{3}$ Monell Chemical Senses Center, Philadelphia, PA

\#These authors have contributed equally to the manuscript.

*Corresponding author: lbankova@bwh.harvard.edu 


\section{ABSTRACT:}

Aeroallergen sensing by airway epithelial cells can trigger pathogenic immune responses leading to chronic type 2 inflammation, the hallmark of airway diseases such as asthma. Airway tuft cells are specialized chemosensory epithelial cells and the dominant source of the epithelial cytokine IL-25 in the trachea and of cysteinyl leukotrienes (CysLTs) in the naïve murine nasal mucosa. The interaction of IL-25 and CysLTs and the contribution of tuft cell-derived CysLTs to the development of allergen-triggered inflammation in the airways has not been clarified. Here we show that inhalation of $\mathrm{LTC}_{4}$ in combination with a subthreshold dose of IL-25 leads to dramatic synergistic induction of type 2 inflammation throughout the lungs, causing rapid eosinophilia, dendritic cell (DC) and inflammatory type 2 innate lymphoid cell (ILC2) expansion, and goblet cell metaplasia. While lung eosinophilia is dominantly mediated through the classical CysLT receptor $\mathrm{CysLT}_{1} \mathrm{R}$, type 2 cytokines and activation of innate immune cells require signaling through both $\mathrm{CysLT}_{1} \mathrm{R}$ and $\mathrm{CysLT}_{2} \mathrm{R}$. Tuft cell-specific deletion of the terminal enzyme requisite for CysLT production, $L t c 4 s$, was sufficient to reduce both the innate immune response in the lung - eosinophilia, KLRG1 ${ }^{+}$ILC2 activation and DC recruitment - and the systemic immune response in the draining lymph nodes after inhalation of the mold aeroallergen Alternaria. Our findings identify surprisingly potent synergy of CysLTs and IL-25 downstream of aeroallergentrigged activation of airway tuft cells leading to a highly polarized type 2 immune response and further implicate airway tuft cells as powerful modulators of type 2 immunity in the lungs.

One Sentence Summary: Tuft cells produce two highly synergistic mediators: TTC $_{4}$ and IL-25 to cooperatively induce allergen-driven airway inflammation. 


\section{INTRODUCTION:}

Type 2 immunity is a host defense mechanism engaged to expel helminths (1) and to repair epithelial cell damage from viral respiratory infections (2). Aeroallergens subvert this system through activation of epithelial cells for release of cytokines (IL-25, IL-33 and TSLP) and danger associated molecular patterns (DAMPs). DAMPs and epithelial cell cytokines act in concert to activate tissue resident dendritic cells (DCs), macrophages and innate type 2 lymphoid cells (ILC2s) to direct and propagate type 2 inflammation leading to chronic airway inflammatory diseases such as asthma and chronic rhinosinusitis $(3,4)$. Besides the classical epithelial cell cytokines, multiple recent studies suggest that DCs and ILC2s are also activated by lipid mediators (5-7) and neuropeptides $(8,9)$. While genetic and immunologic studies have defined barrier epithelial cell pathways that amplify mucosal inflammation, the events that initiate pathogenic immune recognition are still poorly understood.

Airway solitary chemosensory cells are unique epithelial cells that resemble taste bud cells in their expression of taste signaling molecules and have now been universally referred to as tuft cells (10-12). Unlike the chemosensory cells in taste buds, tuft cells are scattered as solitary cells in the epithelium of the upper and lower airway (13). The tuft cells of the airway are characterized by remarkable heterogeneity in morphology and receptor expression, leading to their definition as distinct cellular subsets (11). Tuft cells in the trachea are referred to as cholinergic brush cells (14), a similar population in the nasal respiratory mucosa is termed solitary chemosensory cells (SCCs) (12), and a much more abundant subset of chemosensorylike epithelial cells in the olfactory mucosa are referred to as microvillar cells (MVCs) (15). We recently demonstrated that tracheal brush cells, nasal respiratory SCCs and nasal olfactory MVCs share a core transcriptional profile with tuft cells from other tissue compartments - 
intestinal, thymic and gallbladder tuft cells - suggesting they belong to one large family of chemosensory tuft cells with tissue specific differences mostly in bitter and sweet taste receptor expression (16-18). Among the shared markers of all airway tuft cells from the nasal olfactory, respiratory and tracheal mucosa are TRPM5, required for $\mathrm{Ca}^{2+}$ triggered signal transduction in sweet and bitter taste receptor expressing cells $(12,13,15,16,19)$, the epithelial cytokine IL-25 $(20,21)$, the enzyme choline acetyltransferase (ChAT) for acetylcholine generation (14) and the transcription factor $\operatorname{Pou} 2 f 3(17,18,22)$. Notably, a core transcriptional feature of all tuft cells are the transcripts encoding the lipoxygenase (Alox5, Alox5ap and Ltc4s) and cyclooxygenase (Ptgs1 and Hpgds) pathway enzymes $(11,16,23,24)$. We recently reported the functional capacity of tuft cells to generate high levels of cysteinyl leukotrienes (CysLTs), the major products of the lipoxygenase pathway (16), ex vivo at a level exceeding that of naïve hematopoietic cells in the naïve nasal mucosa. Aeroallergens like the mold aeroallergen Alternaria and the dust mite allergen Dermatophagoides pteronyssinus trigger a P2y2 receptor-dependent autocrine loop leading to generation of CysLTs from tuft cells (16). Although we had demonstrated that airway tuft cells can generate CysLTs in response to allergens, how tuft cell-derived CysLTs regulate allergen-triggered type 2 immunity in the airways has not been defined.

CysLTs are named for their canonical generation by leukocytes recruited or activated in the setting of established inflammation. Following receptor-mediated $\mathrm{Ca}^{2+}$ flux, phospholipase A2 (PLA2 $\alpha$ ) releases phospholipids at the outer nuclear membrane to generate free arachidonic acid. Arachidonic acid is metabolized by the cyclooxygenase and lipoxygenase pathways to prostaglandins and cysteinyl leukotrienes, respectively. The first enzyme of the lipoxygenase pathway, 5-lipoxygenase (5-LO), oxidizes arachidonic acid in the presence of 5-LO activating protein (FLAP) to generate leukotriene $\mathrm{A}_{4}\left(\mathrm{LTA}_{4}\right)$, which is subsequently converted to $\mathrm{LTC}_{4}$ by 
leukotriene $\mathrm{C}_{4}$ synthase $\left(\mathrm{LTC}_{4} \mathrm{~S}\right)(25) . \mathrm{LTC}_{4}$ is rapidly exported by the ATP-dependent multidrug resistance protein 1 (MRP1) and converted within minutes to $\mathrm{LTD}_{4}$, which in turn is rapidly metabolized to $\mathrm{LTE}_{4}$, a more stable but less potent terminal CysLT product (26). CysLTs exert their effects through three G-protein coupled receptors. CysLT ${ }_{1} \mathrm{R}$ has high affinity for $\mathrm{LTD}_{4}(\mathrm{Kd} \sim 1 \mathrm{nM})$ and binds $\mathrm{LTC}_{4}$ with lesser affinity, and can transduce signals to $\mathrm{LTE}_{4}$ as well (27). CysLT 2 R, which is resistant to currently available pharmacotherapy, targeting CysLT 1 R binds $\mathrm{LTC}_{4}$ and $\mathrm{LTD}_{4}$ at equimolar concentrations (28). CysLT 3 R (OXGR1 or GPR99) is a high affinity receptor for $\mathrm{LTE}_{4}$ (29). CysLTs potently augment established type 2 lung inflammation $(30,31)$. This might be at least partially explained by the ability of CysLTs to potentiate the effects of epithelial cytokines. LTC $_{4}$ synergizes with IL-33 for ILC2 activation in the airways and associated lung eosinophilia through $\mathrm{CysLT}_{1} \mathrm{R}$-mediated NFATc translocation (5-7). $\mathrm{LTC}_{4}$ also has $\mathrm{CysLT}_{1} \mathrm{R}$-mediated additive effects on IL-25-induced activation of intestinal ILC2s in vitro (32). The fact that tuft cells generate both $\mathrm{LTC}_{4}$ and IL-25 suggests the potential for these two mediators to facilitate type 2 airway inflammation in vivo, but this possibility has not yet been explored.

Here, we demonstrate that two mediators generated by tuft cells - $\mathrm{LTC}_{4}$ and IL-25 synergize to drive airway type 2 inflammation. Exogenous $\mathrm{LTC}_{4}$ or low dose IL-25 alone only weakly induced inflammation, but the combination of IL-25 and $\mathrm{LTC}_{4}$ administered intranasally strongly induced lung type 2 cytokine expression, as well as lung ILC2 and DC expansion and airway eosinophilia. The proinflammatory synergistic effect of $\mathrm{LTC}_{4}$ and IL-25 is reduced in mice lacking the two receptors for $\mathrm{LTC}_{4}-C y s l t r 1^{-/}$and Cysltr2 $2^{-/-}$with a dominant effect of CysLT $_{1} \mathrm{R}$ in regulating eosinophil recruitment. Tuft cell-targeted deletion of the terminal CysLT biosynthetic enzyme, $L t c 4 s$, in $C h a t^{C r e} L t c 4 s^{f l f l}$ mice led to a specific reduction of CysLT 
generation in tuft cells while preserving their homeostatic transcriptional profile and leaving other CysLT sources unaffected. While $L t c 4 s$ deletion ablated the ability of tuft cells to generate CysLTs, it did not diminish their ability to respond to ATP with generation of $\mathrm{PGD}_{2}$, a cyclooxygenase pathway-derived eicosanoid that is also involved in type 2 inflammation. The early lung eosinophilia and the associated lung draining lymph node hyperplasia triggered by the inhalation of the mold aeroallergen Alternaria was reduced in $C h a t^{C r e} L t c 4 s^{f l f l}$ mice, as was ILC2 activation and expansion in the lung and lung DC expansion. Thus, tuft cells are unique epithelial effector cells capable of inducing eosinophilic type 2 lung inflammation through synergistic cytokine and lipid mediator signaling. 


\section{RESULTS:}

\section{Exogenous LTC 4 dramatically amplifies IL-25 induced lung inflammation}

The role of tuft cells as initiators of type 2 inflammation was initially attributed to their production of IL-25 $(20,21,33)$. Our work identified $\mathrm{LTC}_{4}$ as a major product of airway tuft cells after aeroallergen activation. We therefore investigated the behavior of these proinflammatory mediators in vivo. We administered $\mathrm{LTC}_{4}$ alone at a concentration of $1.6 \mathrm{mmol}$, which induces only mild inflammation in naive mice, or low dose IL-25 alone (100 ng or 5 times lower than the dose used for most airway inflammation studies (9)) or a combination of IL-25 and $\mathrm{LTC}_{4}$ to wild-type (WT) mice (Fig. 1A). Intranasal application of low-dose IL-25 or high dose $\mathrm{LTC}_{4}$ induced very mild lung inflammation, while the combination of $\mathrm{LTC}_{4}$ and IL-25 led to an increase of $\mathrm{CD} 45^{+}$cells in the lung (Fig. 1B). The lung infiltrate was dominated by eosinophils, which accounted for $33 \%$ of the hematopoietic cells by fluorescence-activated sorting (FACS) (Fig. 1C, D) and were the most abundant inflammatory cells in the perivascular infiltrate in the lung (S1A, B). When we assessed the ILC2 compartment (Fig. S1C) for changes in response to IL-25 and $\mathrm{LTC}_{4}$, we detected a population of $\mathrm{KLRG}^{+} \mathrm{ICOS}^{+}$Thy $1.2^{+} \mathrm{ILC} 2 \mathrm{~s}$, similar to the previously described inflammatory ILC2s (34) (Fig. 1E). Interestingly, inhaled low dose IL-25 was insufficient to induce this ILC2 subset, but the addition of $\mathrm{LTC}_{4}$ led to a $30 \%$ increase compared to IL-25 or LTC 4 alone (Fig. 1E-G). This expansion was specific to inflammatory ILC2s, as we did not detect a significant change in the number of the unfractionated lin-Thy $1.2^{+}$ILC2s or any of the subsets of KLRG1-ILC2s (Fig. 1H and Fig. S1DF). The IL-25/LTC 4 synergistic increase in lung eosinophilia and inflammatory ILC2 expansion was associated with an expansion of pulmonary DCs (Fig. S1G), particularly the CD301b ${ }^{+}$ subset (Fig. 1I and Fig. S1H). Despite the clear induction of lung inflammation, the number of 
tuft cells assessed in whole tracheal mounts did not change (Fig. 1J), unlike the effect of LTE4 on tracheal tuft cells (20). This suggests that conversion to $\mathrm{LTE}_{4}$ was not responsible for the observed effects of exogenous $\mathrm{LTC}_{4}$ in vivo. Conversely, lung remodeling with significant goblet cell metaplasia was strongly induced by the combination of $\mathrm{LTC}_{4}$ and IL-25 (Fig. 1JK, L). Consistent with the effect on inflammatory cell recruitment and goblet cell metaplasia, $\mathrm{LTC}_{4}+$ IL-25 augmented type 2 cytokine production in the naïve mouse lung over PBS or either mediator alone, with significant increases of three type 2 cytokines - IL-4, IL-5 and IL-13 (Fig. 1M). In addition, we detected a significant increase in lung IL-6 and a small but significant augmentation of TNF- $\alpha$ (Fig. S2A, B). The type 1 cytokine IFN- $\gamma$ was undetectable and IL-17 family member cytokines were not induced (Fig. S2).

Together, this data demonstrates that two highly synergistic pro-inflammatory and airway remodeling pathways can be triggered by the tuft cell mediators IL- 25 and $\mathrm{LTC}_{4}$, and that the presence of $\mathrm{LTC}_{4}$ dramatically reduces the IL-25 dose required to induce type 2 inflammation. Furthermore, tuft cell mediators act in synergy to effectively skew innate inflammation to a type 2 phenotype. 


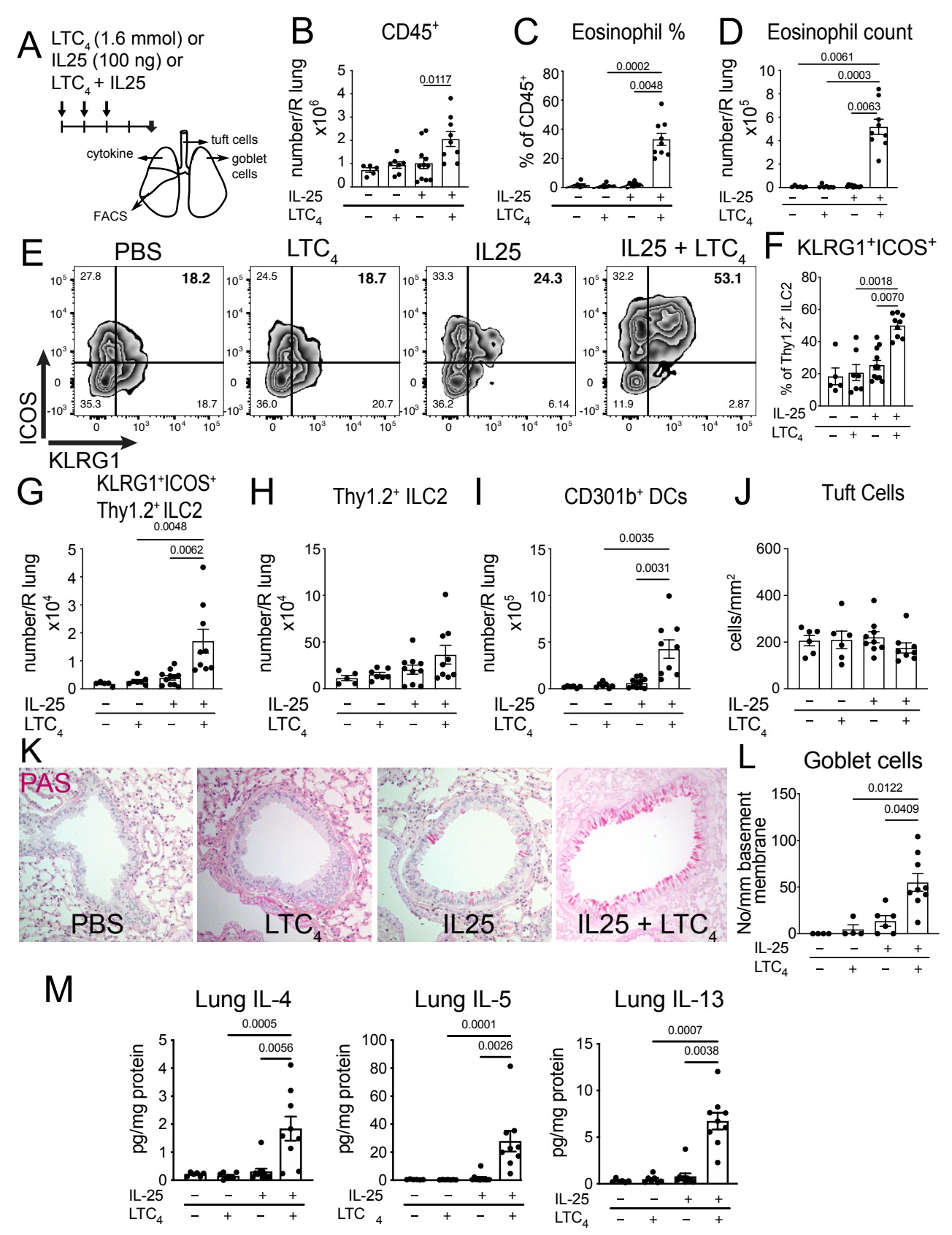

Fig. 1. $\mathrm{LTC}_{4}$ and IL-25 synergize for airway type 2 lung inflammation.

(A) WT mice were given three daily inhalations of $\mathrm{LTC}_{4}(1.6 \mathrm{mmol})$ ' or IL-25 (100 ng) or a combination of $\mathrm{LTC}_{4}$ and IL-25 and assessed 2 days after the last dose. The number of lung CD45 $5^{+}$cells (B), frequency and number of eosinophils $(\mathbf{C}, \mathbf{D})$ frequency and number of KLRG1 ${ }^{+} \mathrm{ICOS}{ }^{+}$Thy $1.2^{+}$ILC2s $(\mathbf{F}$, G), number of unfractionated Thy $1.2^{+} \mathrm{ILC} 2 \mathrm{~s}(\mathbf{H})$ and $\mathrm{CD}^{2} 01 \mathrm{~b}^{+} \mathrm{MHCII}{ }^{+} \mathrm{CD} 11 \mathrm{~b}^{+} \mathrm{DCs}$ (I) were assessed by FACS. (E) Representative FACS plots of KLRG1 and ICOS expression in lin-Thy1.2 $2^{+}$ILC2s. (J) The number of tuft cells was assessed in whole tracheal mounts. (K) Goblet cell metaplasia was assessed in cross sections of the lung with Periodic acid Schiff (PAS) stain and goblet cells were enumerated per mm of basement membrane in the large bronchi $(\mathbf{L})$. (M) Lung cytokine concentration was determined by LegendPlex and calculated per mg of lung protein extracted. Data are means \pm SEM pooled from 3 independent experiments, each dot is a separate mouse, Kruskal-Wallis ANOVA with Dunn's correction for multiple comparisons, $p$ values $<0.05$ indicated. 


\section{The synergy of $\mathrm{LTC}_{4}$ and IL-25 is cooperatively mediated by CysLT $T_{1} R$ and CysLT $T_{2}$.}

To define the CysLT receptors responsible for mediating the synergy of IL-25 and LTC 4 , we evaluated the response in respective strains of mice lacking the three CysLT receptors. This allowed us to account for both the direct effect of $\mathrm{LTC}_{4}$ on $\mathrm{CysLT}_{1} \mathrm{R}$ and $\mathrm{CysLT}_{2} \mathrm{R}$ and of the biosynthetic products $\mathrm{LTD}_{4}$ and $\mathrm{LTE}_{4}$. We found a near complete abrogation of lung inflammation and eosinophil recruitment in Cysltr1 $1^{-/-}$mice (Fig. 2A, B) with marginal nonsignificant reduction of eosinophil counts in Cysltr $2^{-/-}$or Cysltr $3^{-/-}$mice (Fig. 2A, B). Neither CysLT $_{1} \mathrm{R}$ nor CysLT $2 \mathrm{R}$ deletion abolished the specific increase in the percent of $\mathrm{KLRG}^{+} \mathrm{ICOS}^{+}$Thy $1.2^{+}$ILC2 cells induced by $\mathrm{LTC}_{4}+\mathrm{IL}-25$, which suggests a cooperative effect with the IL-25 receptor IL17RB (Fig. 2C, D). While the percent of KLRG $1^{+}$ICOS ${ }^{+}$Thy $1.2^{+}$ILC2 did not change, the absolute number of these inflammatory ILC2s was reduced in both $C y s l t r 1^{-/}$ and Cysltr2 $2^{-/}$mice (Fig. 2E). Thus, although IL17RB signaling is likely a driver of the expansion of inflammatory ILC2s (34), co-signaling with CysLT receptors can trigger the inflammatory ILC2s even at low levels of IL-25. Inflammatory CD301b ${ }^{+}$DCs were reduced in Cysltr1 ${ }^{-/}$, with a non-significant trend toward reduction in Cysltr2 $2^{-/-}$mice (Fig. 2F). Finally, type 2 cytokines were significantly reduced in both $C y s t l r 1^{-/-}$and $C y s t l r 2^{-/-}$mice, with a predominant reduction in Cystlr1 $1^{-/}$mice (Fig. 2G). Collectively, our data highlights the complexity of the CysLT system and implicates two receptors in the effects of $\mathrm{LTC}_{4}$ on target cells. While CysLT $\mathrm{T}_{1} \mathrm{R}$ deletion completely abrogates the synergistic effect of $\mathrm{LTC}_{4}$ and IL-25 on lung eosinophil recruitment and partially reduces the expansion of ILC2s, deleting both $\mathrm{LTC}_{4}$ receptors and the IL-25 receptor IL17RB is likely required to completely abolish the effect of the potent $\mathrm{LTC}_{4} / \mathrm{IL}-25$ synergy. 


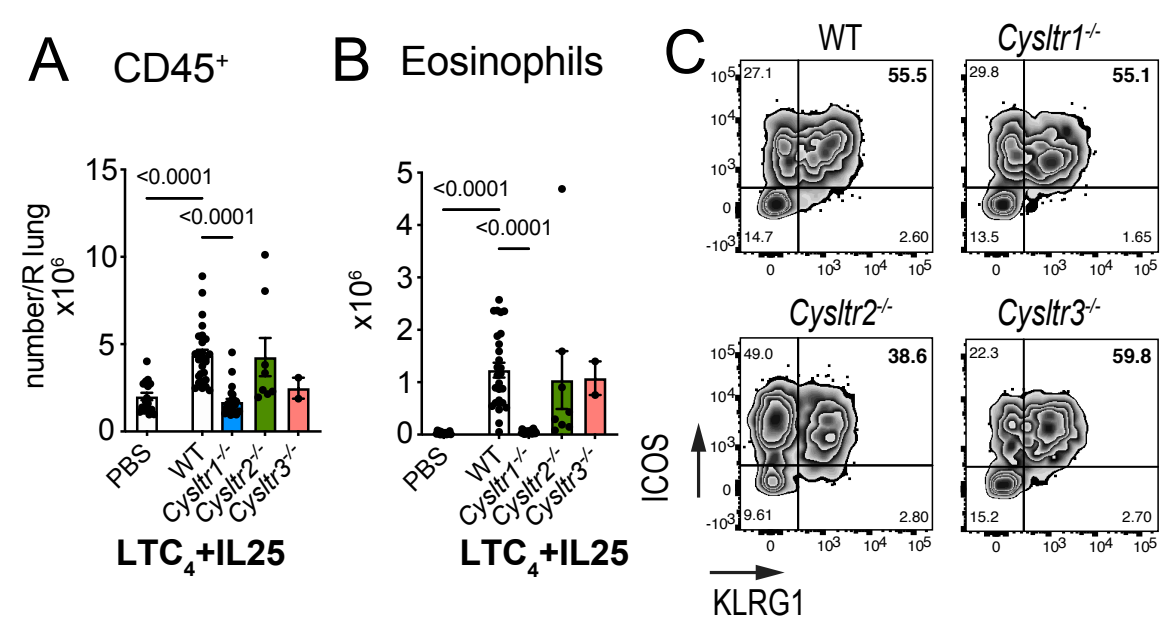

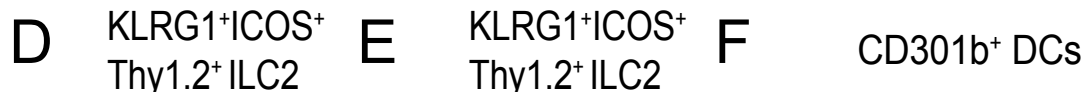

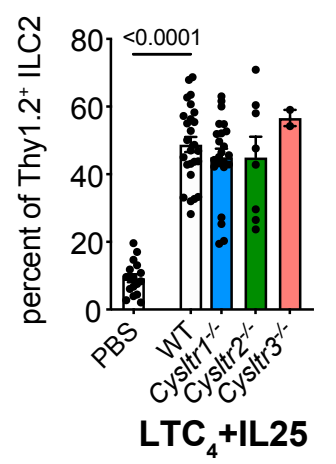

G Lung IL-4

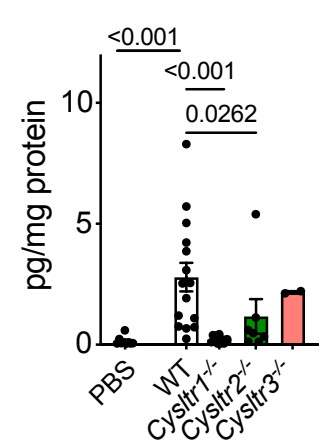

$\mathrm{LTC}_{4}+\mathrm{IL} 25$

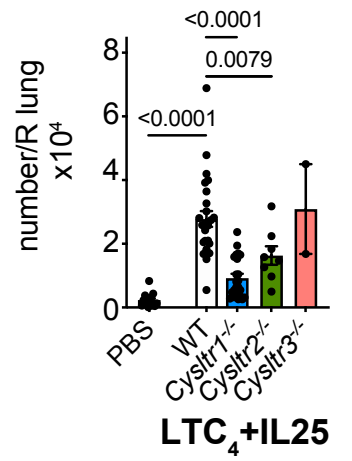

Lung IL-5

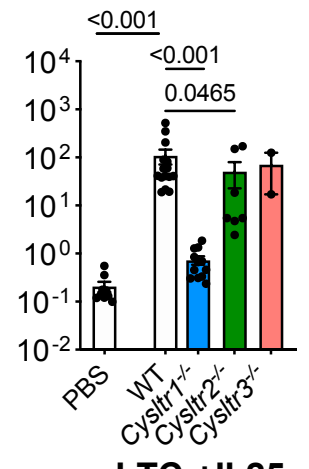

$\mathrm{LTC}_{4}+\mathrm{IL} 25$

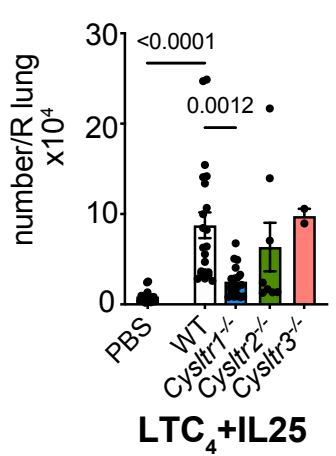

Lung IL-13

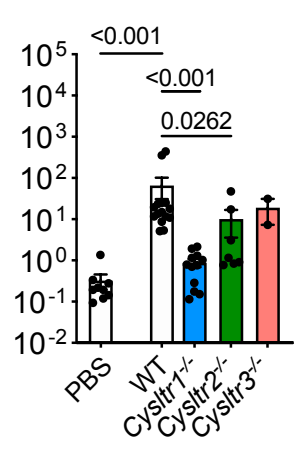

$\mathrm{LTC}_{4}+\mathrm{IL} 25$

Fig. 2. $\mathrm{LTC}_{4}$ potentiation of IL-25-induced type 2 inflammation depends on $\mathrm{CysLT}_{1} \mathrm{R}$ and CysLT $_{2}$ R.

WT (C57BL/6), Cysltr1 ${ }^{-/}$, Cysltr2 $2^{-/}$and Cysltr $3^{-/-}$mice were given three daily inhalations of LTC $_{4}$ and IL-25 daily for 3 days and assessed 2 days after the last dose. Numbers of lung CD45 cells (A), eosinophils (B), frequency and number of KLRG1 ${ }^{+} \mathrm{ICOS}^{+} \mathrm{ILC} 2 \mathrm{~s}(\mathbf{D}, \mathbf{E})$, and number of CD301b $\mathrm{b}^{+}$ CD1 $1 b^{+}$DCs $(\mathbf{F})$ were assessed by FACS. (C) Representative FACS plots of KLRG1 and ICOS expression in lin Thy $1.2^{+}$ILC2s. (G) Cytokine protein concentration was determined by LegendPlex and expressed per mg of lung protein. Data are means \pm SEM pooled from 3 independent experiments, each dot is a mouse, significant $p$ values indicated for each pairwise comparison: Mann Whitney U test. 


\section{ChAT-mediated targeted deletion of $\mathrm{Ltc} 4 \mathrm{~s}$ selectively ablates tuft cell generation of CysLTs.}

To assess the epithelial and immune effector circuit regulated by tuft cell-derived CysLTs, we generated $L t c 4 S^{f l f l}$ mice to enable conditional deletion of $L t c 4 s$. We first characterized the populations of epithelial cells in the nose in the $L t c 4 s^{f l f f l}$ mice and compared them to nasal tuft cells and epithelial cells from ChAT-eGFP mice. In the absence of a fluorescent marker in the $L t c 4 S^{f l f l}$ mice, we used our previously published combination of EpCAM and CD45 expression to isolate tuft cell-enriched populations from the nasal mucosa (16). We isolated EpCAM ${ }^{\text {high }} C D 45^{\text {low }}$ cells to compare them to $\mathrm{EpCAM}^{\text {high }} \mathrm{CD}^{2} 5^{-}$and $\mathrm{EpCAM}^{\text {interm }}$ cells from the same $L t c 4 s^{f l f l}$ mice (Fig. S3A). We then compared these three populations derived from the $L t c 4 s^{f l f l}$ mice to the more pure populations of tuft cells derived from the olfactory and respiratory mucosa of ChAT-eGFP mice. In ChAT-eGFP mice, we had characterized two populations of nasal tuft cells based on their FACS morphology, which share the core transcriptional profile of tuft cells from other mucosal organs, but differ in the expression of taste receptors and roughly correspond to olfactory MVCs and respiratory SCCs (16). Here, we isolated ChAT-eGFP SSC ${ }^{\text {low }}$ tuft cells from the olfactory mucosa and ChAT-eGFP SSC high tuft cells from the respiratory mucosa to more clearly delineate the MVCs and SCCs (Fig. S3B). We confirmed that the transcriptional profile of EpCAM ${ }^{\text {high }} \mathrm{CD} 45^{\text {low }}$ epithelial cells is highly similar to the dominant nasal population of olfactory tuft cells (Fig. 3A and S3C, D). Furthermore, EpCAM ${ }^{\text {high }}$ CD $45^{\text {low }}$ cells share the core transcriptional profile of tracheal tuft cells defined by scRNAseq (11) while EpCAM $^{\text {high }}{ }^{-}{ }^{4} 5^{-}$likely represent a less pure mix of tuft cells and epithelial cells (Fig. $3 B$ ). Both EpCAM $^{\text {high }}$ populations strongly expressed the tuft cell-specific genes Trpm5, Avil, and Pou $2 f 3$ as well as enzymes in the CysLT biosynthetic cascade, including Alox5, Alox5ap and Ltc4s (Fig. 3C, D), with a higher level of all transcripts found in the EpCAM ${ }^{\text {high }} \mathrm{CD} 45^{\text {low }}$ cells. 
We then crossed the $L t c 4 s^{f l f l}$ mice to $C h a t^{C r e}$ mice to specifically delete $L t c 4 s$ in ChATexpressing cells. Classically, cholinergic neurons are the best characterized Chat-expressing cells $(35,36)$. Therefore, to account for possible Chat and Ltc4s coexpression in the central and peripheral nervous system, we interrogated published scRNAseq datasets of the mouse central and peripheral nervous system and detected no expression of $L t c 4 s$ in the main Chat-expressing populations of the nervous system - motor neurons and visceral motor neurons (Fig. S4A). In the brain tissue, Ltc4s was only expressed in immune cell populations. Chat expression in immune cell subsets has been reported in CD8 and CD4 T cells (37) and more recently in ILC2s (38, 39), while among hematopoietic cells in the nasal mucosa, $L t c 4 s$ is reported in macrophages, DCs, and mast cells $(40,41)$. To assess for co-expression of Chat and Ltc4s more broadly in the airway mucosa, we evaluated a recently generated dataset of 50,000 epithelial and immune cells in the nasal mucosa (derived from a recently collected unpublished scRNAseq dataset from our laboratory of epithelial and immune cells from naïve and Alternaria-challenged mice). Several immune cell subsets - including T and B cell subsets, ILC2s and macrophages - expressed Chat, while macrophages, eosinophils, and DCs expressed $L t c 4 s$ as expected (Fig. S4B). Remarkably, only the tuft cells expressed both Chat and $L t c 4 s$ in $>10 \%$ of the cells (Fig. S4B). Consistent with this co-expression, ChAT ${ }^{\mathrm{Cre}}$ mediated deletion of $L t c 4 s$ led to a profound $95 \%$ reduction of $L t c 4 s$ in the EpCAM ${ }^{\text {high }} C D 45^{\text {low }}$ tuft cell-enriched population and a $90 \%$ reduction in the EPCAM $^{\text {high }}{ }^{-}{ }^{4} 5^{-}$cells (Fig. 3E, F). To confirm that $L t c 4 s$ expression was not affected in macrophages and DCs, we isolated both immune cell subsets from $L t c 4 s^{f f f l}$ and $C h a t^{C r e} L t c 4 s^{f f l l}$ mice (Fig. S4C). Macrophages expressed $L t c 4 s$ at similarly high levels as tuft cells with no reduction in $L t c 4 s$ expression in $C h a t^{C r e} L t c 4 s^{f l f l}$ mice (Fig. 3F). DC expression of $L t c 4 s$ was magnitudes lower than that of macrophages and tuft cells and was not significantly affected in 
Chat ${ }^{\text {Cre }} L t c 4 s^{f l f l}$ mice (Fig. S4D). Thus, ChAT ${ }^{\text {Cre }}$ mediated deletion of $L t c 4 s$ effectively ablated expression of the $L t c 4 s$ transcript in tuft cells without an effect on other epithelial, neuronal or immune cell subtypes.

To probe for homeostatic effects of $L t c 4 s$ deletion on tuft cells, we compared the transcriptional profile of EpCAM ${ }^{\text {high }} \mathrm{CD} 45^{\text {low }}$ tuft cells from $L t c 4 s^{\text {flffl }}$ and Chat ${ }^{C r e} L t c 4 s^{f l f l}$ mice. While $L t c 4 s$ expression was $95 \%$ reduced in the tuft cell-enriched $\mathrm{EpCAM}^{\mathrm{high}} \mathrm{CD} 45^{+}$cells of Chat ${ }^{C r e} L t c 4 s^{f l f l}$ mice, we detected a very limited effect on the homeostatic transcriptional profile of this tuft cell-enriched population besides $L t c 4 s$ (Fig. 3E). EpCAM ${ }^{\text {high }}$ CD $45^{\text {low }}$ tuft cells from Chat ${ }^{\text {Cre }} L t c 4 s^{f l f l}$ mice clustered together with EpCAM ${ }^{\text {high }}$ CD $45^{\text {low }}$ tuft cells from $L t c 4 s^{f l f l}$ mice, suggesting no significant transcriptional changes (Fig. S5A, B). In addition, tuft cell numbers in EpCAM ${ }^{\text {high }} C D 45^{\text {low }}$ cells in the nose did not differ significantly between $L t c 4 s^{f l f l}$ and Chat ${ }^{C r e} L t c 4 S^{f l f l}$ mice (Fig. S5C). Further, deletion of $L t c 4 s$ in tuft cells did not affect the homeostatic expression of other eicosanoid biosynthetic enzymes in tuft cells (Fig. 3G and Fig. S5D). Finally, expression of the other major effector mediator generated by tuft cells, Il25, and the expression of $\mathrm{P} 2 \mathrm{Y} 2 \mathrm{R}$, involved in allergen recognition by tuft cells (16), were not reduced by the tuft cell-specific deletion of $L t c 4 s$ (Fig. 3G). Collectively, we found that ChAT $^{\mathrm{Cre}}$-mediated deletion of $L t c 4 s$ in tuft cells specifically targets $L t c 4 s$ with minimal effect on the tuft cell homeostatic transcriptional profile. 

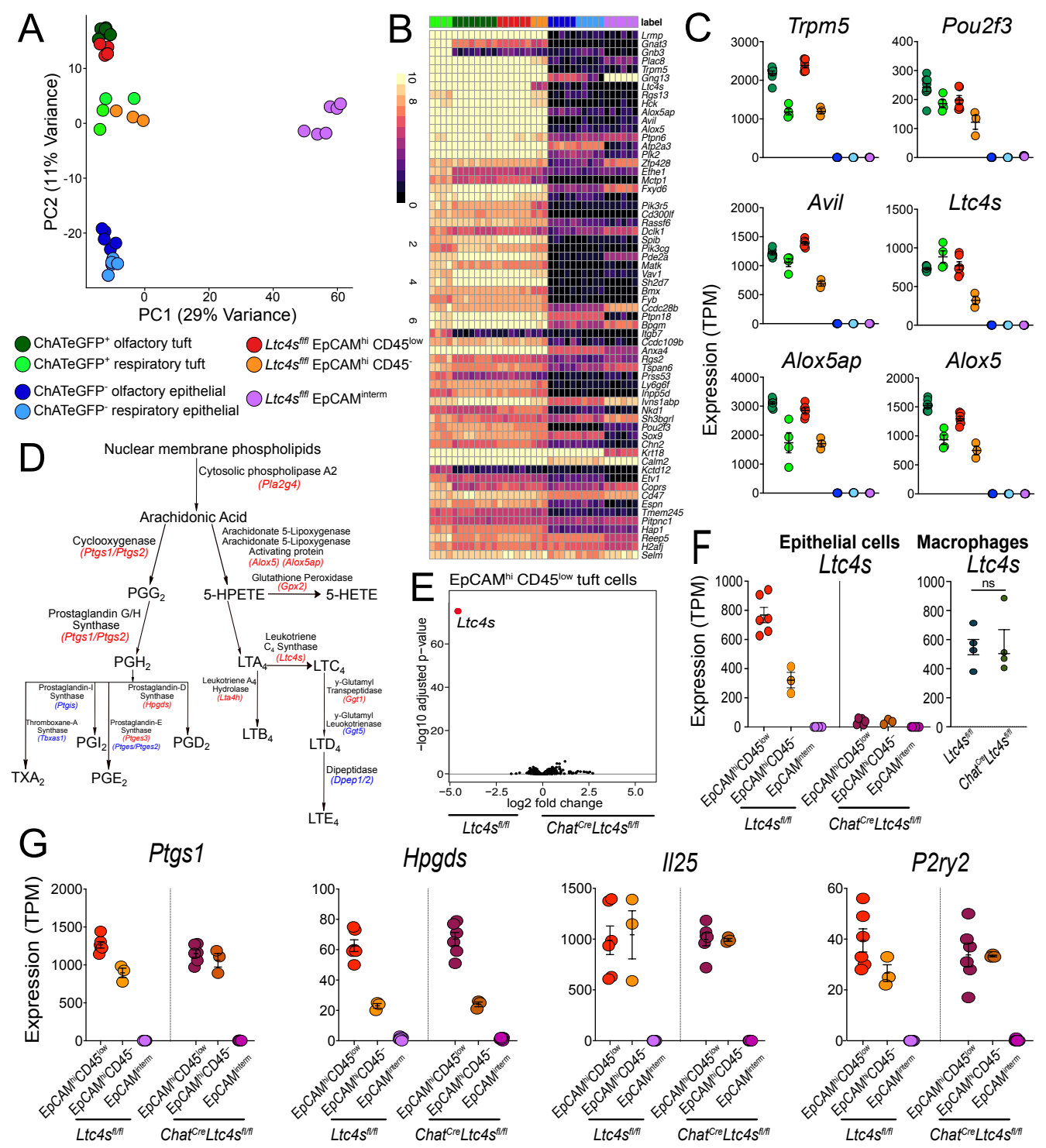

Fig. 3. Essential features of the tuft cell transcriptome are preserved after specific deletion of $\mathbf{L t c 4 s .}$ Tuft cells and epithelial cells were isolated from the naïve nasal mucosa of ChAT-eGFP, $L t c 4 s^{f l f l}$ and $C h A T^{\text {Cre }} L t c 4 s^{\text {flflfl }}$ mice. Tuft cells were defined as EpCAM ${ }^{\text {high }} \mathrm{GFP}^{+} \mathrm{SSC}^{\text {low }}$ olfactory tuft and EpCAM $^{\text {high }} \mathrm{GFP}^{+} \mathrm{SSC}^{\text {high }}$ respiratory tuft in ChAT-eGFP mice and compared with EpCAM ${ }^{\text {high }} \mathrm{CD} 45^{\text {low }}$ and EpCAM ${ }^{\text {high }} \mathrm{CD} 45^{-}$and EpCAM ${ }^{\text {interm }}$ epithelial cells from $L t c 4 s^{f l f f l}$. (A) Principal components analysis comparing each of the above populations of cells from ChAT-eGFP mice and control $L t c 4 s^{f l f l}$ mice. Numbers indicate frequency of transcripts described by each principal component (PC). (B) Expression of the tracheal scRNAseq signature (11) genes across tuft and non-tuft epithelial cells in the nose. (C) TPM counts of the indicated genes derived from RNA seq analysis using DeSeq2 showing tuft cell specific genes. (D) Eicosanoid pathway enzymes and transcripts (in italics). Highlighted in red are transcripts expressed in tuft cells in RNAseq datasets, and in blue, transcripts that were not detected. (E) Volcano plot displaying significance (y axis, - $\log 10(\mathrm{FDR})$ ) of differential expression ( $\mathrm{x}$ axis, log2 fold-change) in EpCAM ${ }^{\text {high }} \mathrm{CD} 45^{\text {low }}$ tuft cell-enriched cells between $L t c 4 s^{f l / f l}$ and Chat ${ }^{C r e} L t c 4 s^{\text {flflfl }}$ mice. (F) Ltc $4 s$ expression in with EpCAM ${ }^{\text {high }} \mathrm{CD} 45^{\text {low }}$ and $\mathrm{EpCAM}^{\text {high }} \mathrm{CD} 45^{-}$and $\mathrm{EpCAM}^{\text {interm }}$ epithelial cells and macrophages derived from $L t c 4 s^{f l l f l}$ and $C h a t^{C r e} L t c 4 s^{f l f l f}$ mice, ns = not significant (G) Expression level (TPM) of the indicated genes derived from RNA seq analysis using DeSeq2 of EpCAM ${ }^{+}$cells from $L t c 4 s^{f l l f l}$ and $C h a t^{C r e} L t c 4 s^{f l f l}$ mice. 
To confirm that the $L t c 4 s$ transcript deletion leads to a specific impairment of CysLT generation, we isolated nasal EpCAM ${ }^{\text {high }} \mathrm{SSC}^{\text {low }}$ epithelial cells from $C h a t^{C r e}, \operatorname{Ltc} 4 \mathrm{~s}^{\mathrm{fl} f \mathrm{fl}}$ and Chat ${ }^{\text {Cre }} \mathrm{Ltc}_{\mathrm{S}} \mathrm{s}^{\mathrm{fl} f l}$ mice and assessed their responses to $\mathrm{Ca}^{2+}$ ionophore and the physiologic tuft cell stimulus ATP using an ex vivo stimulation assay (16). Tuft cells isolated from both Chat ${ }^{\text {Cre }}$ and $L t c 4 s^{f l f l}$ mice generated high levels of CysLTs in response to $\mathrm{Ca}^{2+}$ ionophore, and this response was almost entirely absent in tuft cells from $C h a t^{C r e} L t c 4 s^{f l f l}$ mice (Fig. 4A). CD $45^{+}$cells isolated from $L t c 4 s^{f l f l}$ and $C h a t^{C r e} L t c 4 s^{f l f l}$ mice stimulated with $\mathrm{Ca}^{2+}$ ionophore generated CysLTs at comparable levels, confirming the specificity of $L t c 4 s$ deletion to tuft cells (Fig. 4B). Stimulation with ATP, a physiologic stimulus of tuft cells through the P2Y2 receptor (16), similarly elicited CysLTs from tuft cells isolated from $L t c 4 s^{f l f l}$ but not from $C h a t^{C r e} L t c 4 s^{f l f l}$ mice (Fig. 4C). Consistent with the RNAseq data demonstrating preserved cyclooxygenase biosynthetic transcripts, Chat ${ }^{C r e} L t c 4 s^{f l f l}$ derived tuft cells stimulated with both the $\mathrm{Ca}^{2+}$ ionophore A23187 and with ATP generated $\mathrm{PGD}_{2}$ at levels comparable to tuft cells sorted from $L t c 4 s^{f l / f l}$ and $C h a t^{C r e}$ mice (Fig. 4D, E). We could not verify the effect of CysLT deletion on IL-25 production at the protein level, but confirmed that IL-25 transcript was not reduced in these Chat ${ }^{\text {Cre }}$ Ltc $\mathrm{S}^{\mathrm{fl} l f l}$ mice (Fig. 3G). We had previously shown that tuft cells are the dominant source of Alternariatriggered nasal CysLTs in vivo using mice with deletion of the tuft cell-specific transcription factor Pou2f3 (16). Here, intranasal Alternaria administered in vivo to $L t c 4 s^{f l f l}$ mice induced generation and luminal release of CysLTs into the nasal lavage fluid, which was reduced in Chat ${ }^{C r e} L t c 4 s^{f l f l}$ mice, confirming that $L t c 4 s$ expressed in tuft cells is a critical contributor to the innate nasal $\mathrm{LTC}_{4}$-generating response to aeroallergens (Fig. 4F).

Collectively, these data demonstrate that Chat $^{\text {Cre }}$-mediated deletion of Ltc 4 s specifically ablates the ability of tuft cells to generate CysLTs but does not alter their numbers, 
transcriptional profile, or potential to sense environmental danger signals and respond with generation of eicosanoids.

\section{A Tuft cell CysLTs B CD45+CysLTs C Tuft cell CysLTs}
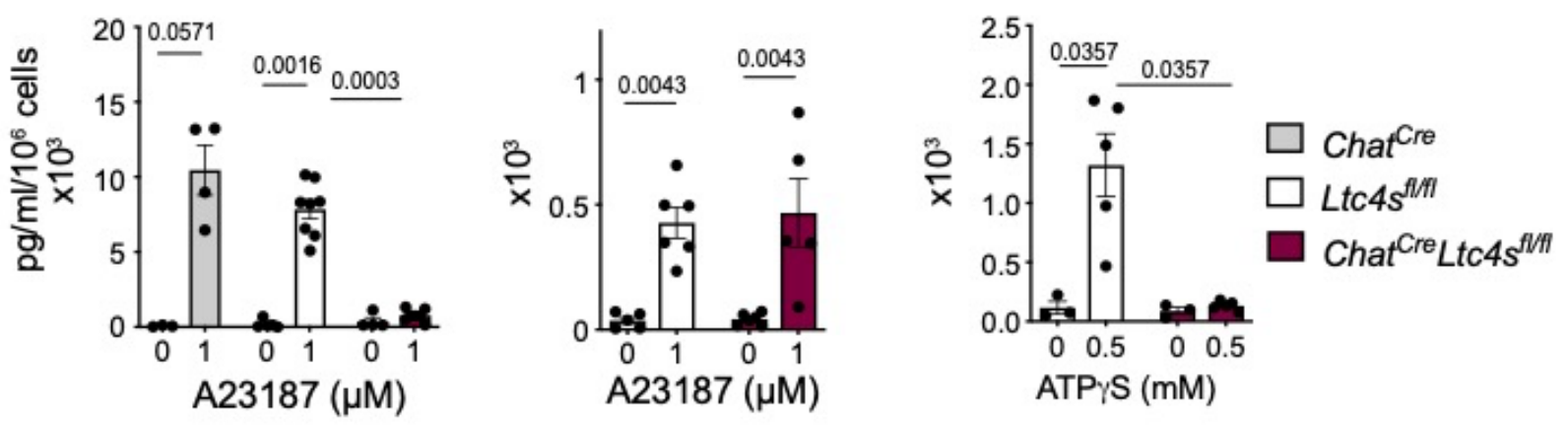

D Tuft cell $P \mathrm{DD}_{2} \quad \mathrm{E}$ Tuft cell $\mathrm{PGD}_{2} \mathrm{~F}$ Nasal lavage CysLTs
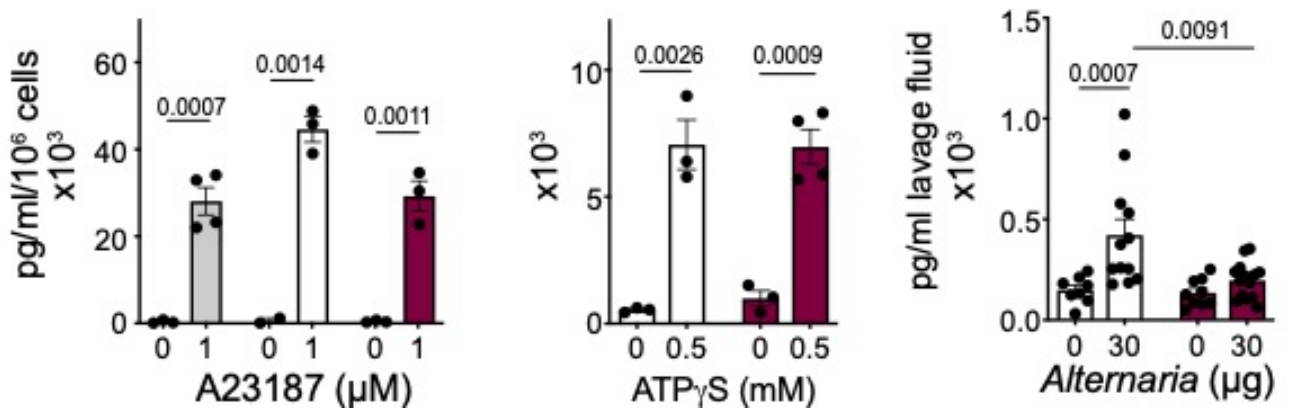

Fig. 4. Tuft cell-specific $L t c 4 s$ deletion does not alter their ability to respond to activating signals.

(A-E) EpCAM ${ }^{\text {high }} \mathrm{CD} 45^{\text {low }} \mathrm{SSC}^{\text {low }}$ tuft cells $(\mathbf{A}, \mathbf{C}-\mathbf{E})$ or $\mathrm{CD}^{4} 5^{+}$cells $(\mathbf{B})$ were isolated from the nasal mucosa of Chat ${ }^{C r e}, L t c 4 s^{f l f l}$ and Chat ${ }^{C r e} L_{t c} 4 s^{\text {flfl }}$ mice and stimulated ex vivo with $\mathrm{Ca}^{2+}$ ionophore (A23187) (A, B, D) or ATP $\gamma \mathrm{S}(\mathbf{C}, \mathbf{E})$. The concentration of CysLTs (A-C) or PGD 2 $(\mathbf{D}, \mathbf{E})$ in the supernatants was measured by ELISA at $30 \mathrm{~min}$. (F) Alternaria was administered intranasally to naïve $L t c 4 s^{f l f l}$ and $C h a t^{C r e} L t c 4 s^{f l f l}$ mice and nasal lavage (NL) was obtained at 30 min. The concentration of CysLTs (F) were measured by ELISA after acetone precipitation. Data are means \pm SEM, from at least three independent experiments, each dot represents a separate biological replicate representing pooled cells from 1-3 mice, Mann Whitney U-test $p$ values $<0.05$ are indicated. 


\section{Alternaria-induced ILC2 and DC expansion depends on tuft cell-derived CysLTs.}

We have previously shown that tuft cells are directly activated by aeroallergens to generate CysLTs (16). Here we confirm the physiological importance of this finding by showing that tuft cell-specific deletion of $L t c 4 s$ leads to significant decrease of overall CysLT generation in the naïve nasal mucosa (Fig. 4F). To determine how tuft cell-derived CysLTs regulate the airway immune response to inhaled allergens, we administered the aeroallergen Alternaria to tuft cell-specific CysLT-ablated Chat ${ }^{C r e} L t c 4 s^{f l f l}$ mice and $L t c 4 s^{f l f l}$ controls (Fig. 5A). Overall Alternaria-induced lung inflammation was reduced in Chat ${ }^{C r e} L t c 4 s^{f l f l}$ mice (Fig. 5B), confirming the importance of tuft cell-derived CysLTs in this response.

Our exogenous IL-25+LTC 4 inhalation data suggested that ILC2s and DCs were prominently affected by CysLTs. Consistent with that finding, both local expansion of $\mathrm{KLRG}^{+} \mathrm{ICOS}^{+} \mathrm{ILC} 2 \mathrm{~s}$ and their expression of the activation marker ICOS were reduced in Alternaria-challenged Chat ${ }^{\text {Cre }} L t c 4 s^{f l f l}$ mice (Fig. 5C, D). Similar to our pharmacologic model, we found a reduction in the recruitment of DCs to the lung (Fig. 5E). Thus, in an aeroallergentriggered airway inflammation model where CysLTs are produced early in the tissue response, the targeted deletion of CysLT generation in tuft cells diminishes the local activation and expansion of two critical innate immune cell types. Alternaria-induced lung inflammation is also reduced in the absence of IL-25 signaling (20) at the same time point. Thus, to account for the IL-25 component of the LTC 4 /IL-25 synergy and determine whether the LTC $4 /$ IL-25 synergy requires an intact $\mathrm{LTC}_{4}$ biosynthetic pathway in tuft cells, we administered $\mathrm{LTC}_{4}$ and IL-25 alone or in combination (as in Fig. 1A) to Chat ${ }^{C r e} L t c 4 s^{f l f l}$ mice. Lung eosinophilia,

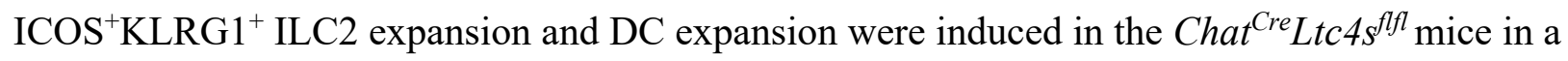
synergistic fashion similar to what we observed in WT mice (Fig. S6). To further probe if IL-25 
signaling might be disrupted in the absence of endogenous CysLTs and account for all possible sources of $\mathrm{LTC}_{4}$, we administered a higher dose of IL-25, sufficient to induce in vivo activation of ILC2s (9) and DCs (42), to WT and mice with germline deletion of Ltc4s. Intranasal IL-25 (500 ng) induced ILC2 expansion and activation as well as DC recruitment and tuft cell number increase in the trachea, all of which were intact in $L t c 4 s^{-/-}$mice (Fig. S7). The preserved response to IL-25 in the absence of $\mathrm{LTC}_{4} \mathrm{~S}$ suggests that IL-25 autocrine signaling in tuft cells is not a major contributor to their proinflammatory function via CysLT production. This suggests that IL-25 and CysLTs are generated by tuft cells in response to aeroallergen activation and synergistically activate innate immune cells to promote lung inflammation.

Alternaria inhalation leads to both lung inflammation and tracheal epithelial remodeling with tuft cell expansion that is dependent on endogenous CysLTs (20). Here, we found that Alternaria inhalation led to expansion of tuft cells in the trachea of WT $L t c 4 s^{f l f l}$ mice while no tuft cell expansion was observed in $C h a t^{C r e} L t c 4 s^{f l f l}$ mice (Fig. 5F, G). Tuft cell-specific deletion of CysLTs was associated with a higher baseline number of tuft cells, which is consistent with our previous data in $L t c 4 s^{-/}$mice and points to the tuft cell as the major source of CysLTs that regulate the tracheal remodeling. Collectively, we demonstrate that endogenously generated CysLTs from tuft cells are required for both inflammation and airway tissue remodeling in response to an inhaled aeroallergen. 

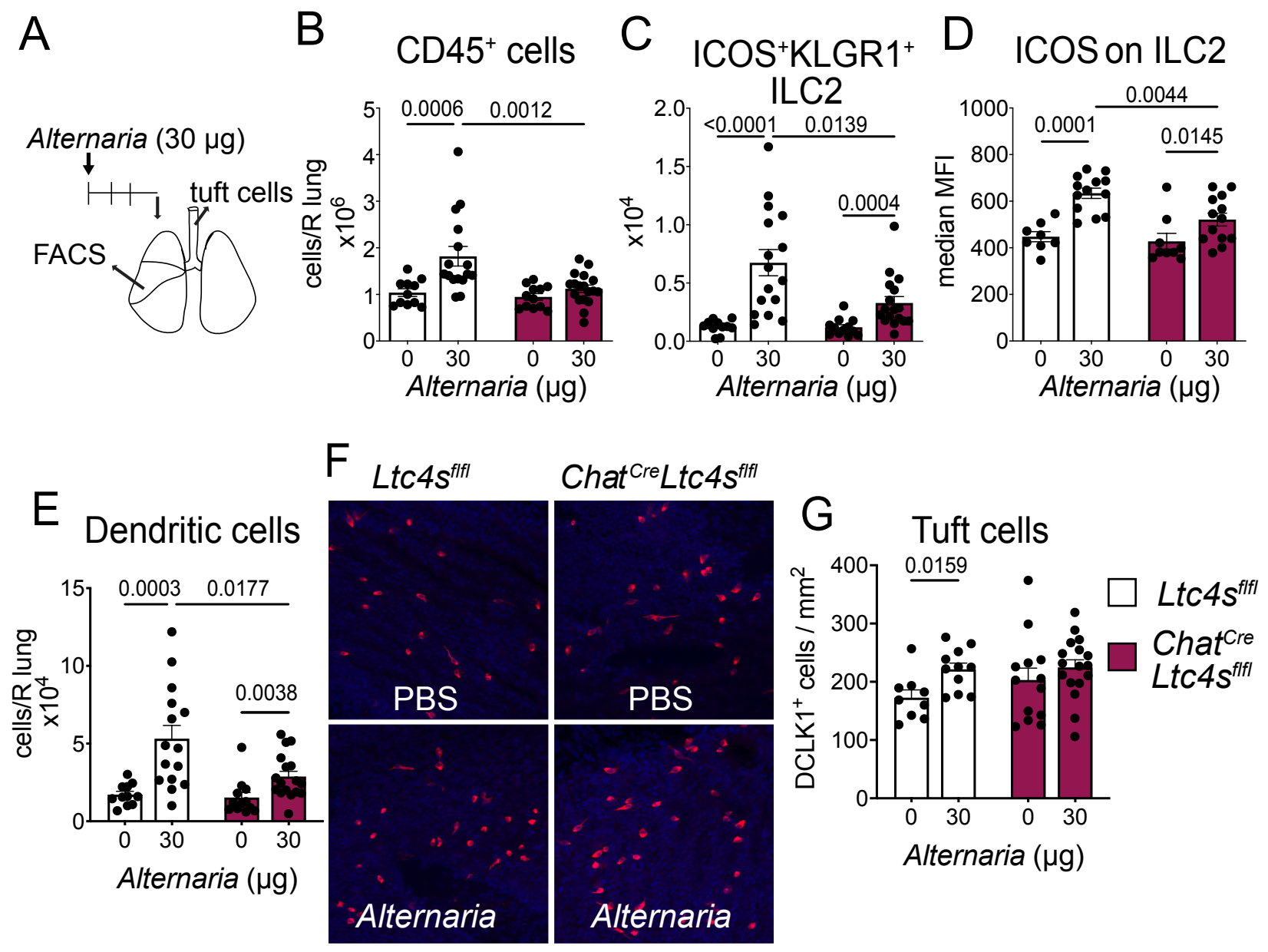

Fig. 5. Tuft cell-derived CysLTs regulate ILC2 expansion in the lung. (A-B) $L t c 4 S^{f l f l}$ and Chat ${ }^{C r e} L t c 4 s^{f l f l}$ mice were given a single intranasal administration of Alternaria. Tracheal tuft cells and lung inflammation were evaluated 72 hours after challenge (A). Flow cytometry analysis of dispersed lung cells showing total hematopoietic cell numbers $\left(\mathrm{CD} 45^{+}\right)(\mathbf{B})$, ILC2 numbers $\left(\mathrm{CD}^{4} 5^{+} \mathrm{lin}^{-}\right.$Thy $\left.1.2^{+} \mathrm{KLRG1}^{+} \mathrm{ICOS}^{+}\right)(\mathbf{C})$, KLRG1 MFI (D) and DCs $\left(\mathrm{CD}^{4} 5^{+} \mathrm{SiglecF}^{-}\right.$

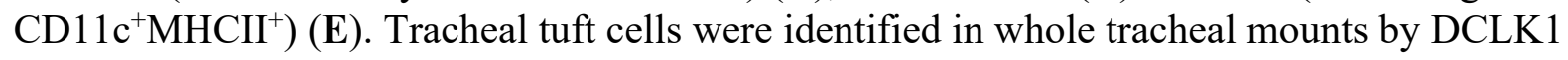
immunoreactivity. Representative images $(\mathbf{F})$ and quantitation of tuft cell numbers in the trachea (G). Data are means \pm SEM, from at least three independent experiments, each dot represents a separate mouse, Mann Whitney U-test $p$ values $<0.05$ are indicated. 


\section{Early lung eosinophilia and systemic immune response triggered by Alternaria depend on tuft cell-derived CysLTs.}

To further define the steps of the local and systemic immune response that depend on tuft cell-derived CysLTs, we evaluated the early response to Alternaria 24 hours after a single intranasal inhalation $(6,16,43)$. Bronchoalveolar lavage (BAL) eosinophilia was induced in $L t c 4 s^{f l f l}$ mice at 24 hours and significantly reduced in $C h a t^{C r e} L t c 4 s^{f l / f l}$ mice. The low-level recruitment of neutrophils at this time point was not affected by the deletion of $L t c 4 s$ in tuft cells (Fig. 6A). The $70 \%$ reduction of BAL eosinophilia in Chat ${ }^{C r e} L t c 4 s^{f l f l}$ mice was similar to the reduction we had previously reported in tuft cell-deficient Pou $23^{-/}$mice (16). Mice with germline deletion of $L t c 4 s$ had a similar degree of reduction in eosinophilia as Chat ${ }^{\text {Cre }} L t c 4 s^{f l f l}$ mice, with marginal effect on the variable rapid lung neutrophil recruitment (Fig. 6B). Since Alternaria inhalation is also associated with resident innate mast cell activation, we also evaluated mast cell-deficient mice (43). Mice with Mcpt5Cre-mediated diphtheria toxin ablation of innate mast cells showed a degree of reduction in BAL eosinophilia that was similar to mice with tuft cell-specific and germline deletion of $L t c 4 s$ (Fig. 6B).

To evaluate the relative contribution of tuft cell-derived CysLTs to the systemic immune response, we assessed the lymph node response 24 hours after a single dose of Alternaria. We compared mice with tuft cell-specific deletion of Ltc $4 s$ to tuft cell-deficient Pou $2 f 3^{-/-}$mice to account for differences attributable to other tuft cell-derived mediators, including IL-25 and $\mathrm{PGD}_{2}$. The Alternaria-elicited lung draining lymph node hyperplasia was significantly reduced in $C h a t^{C r e} L t c 4 S^{f l f l}$ and Pou $23^{-/-}$mice 56\% and 53\% respectively, pointing to a role of tuft cellderived CysLTs in systemic immunity. We found no significant difference between tuft celldeficient mice and mice with tuft cell-specific deletion of $L t c 4 s$ (Fig. 6C). Disrupted CysLT 
generation in tuft cells had a generalized effect on the proliferation and recruitment of $\mathrm{CD}^{+}$and $\mathrm{CD}^{+} \mathrm{T}$ cells and B cells (Fig. 6C), which mirrored the reduction in the lymph node response found in $L t c 4 S^{-/-}$mice with germline deletion of $L t c 4 s$ (Fig. 6D). Mast cell-deficient mice had a borderline but non-significant reduction in lymph node hyperplasia, suggesting that the tuft cellgenerated $\mathrm{LTC}_{4}$ accounts for the CysLT-dependent effects in the lymph nodes.

In summary, we find that despite the low densities of tracheal tuft cells relative to the nasal mucosa, tuft cell-derived CysLTs are required for eosinophilic inflammation throughout the lungs and contribute to the development of the systemic immune response to aeroallergens. 


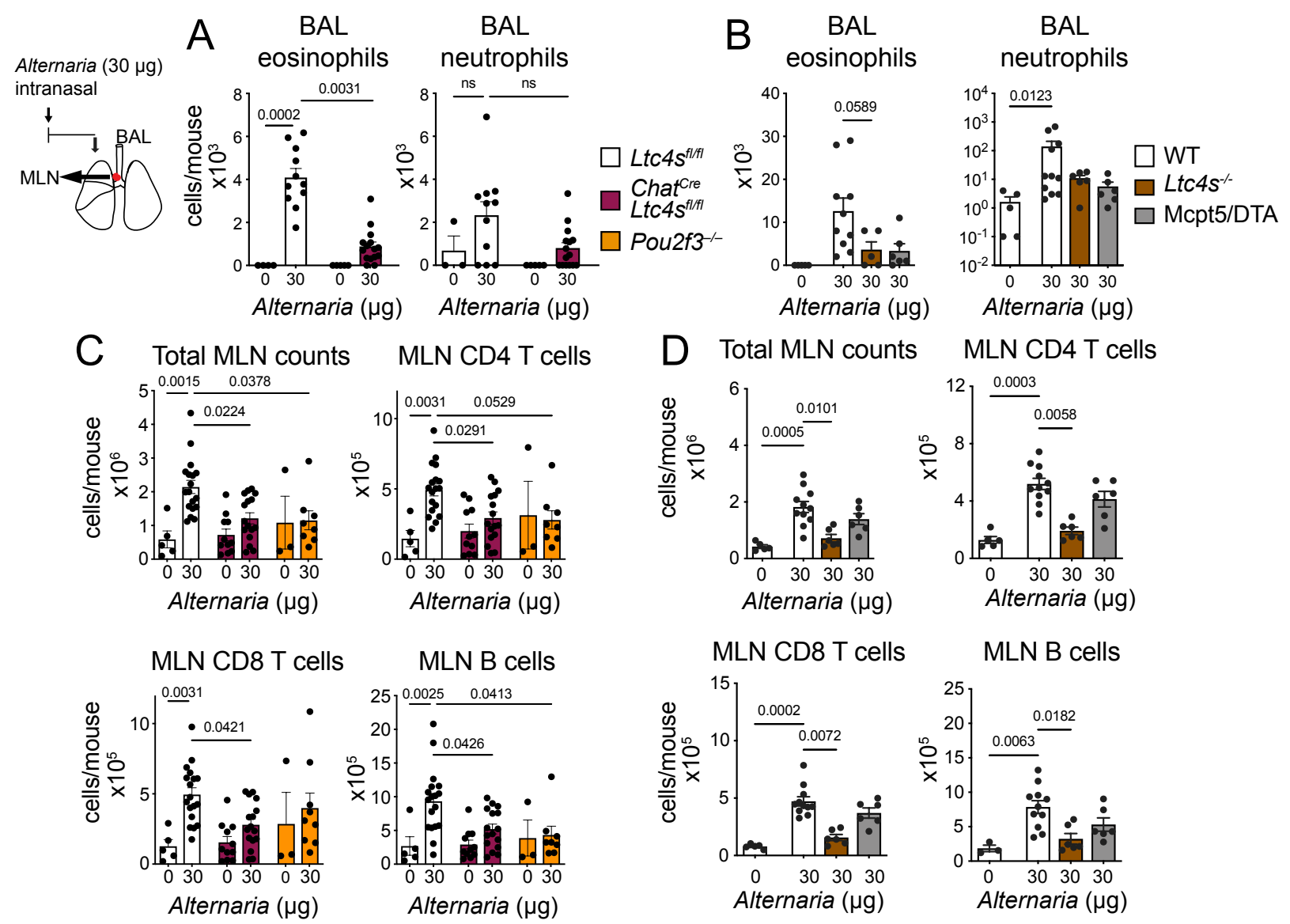

Fig. 6. Tuft cell-derived CysLTs contribute to Alternaria-induced early eosinophilia and systemic immunity.

WT (C57BL/6 and Ltc4s $\left.4 s^{f l f l}\right)$, Chat ${ }^{C r e} L t c 4 s^{f l f l}$, Pou2f3 ${ }^{-/-}$(A, C), Ltc $4 s^{-/-}$and Mcpt5/DTA mice (B, D) were given a single intranasal dose of Alternaria and were evaluated 24 hours after the challenge. The total number of cells in the BAL lavage were counted, and differential subsets were evaluated using Diff-Quick (A, B). Lung draining mediastinal lymph nodes (MLN) were harvested and the LN cell subsets were evaluated by FACS (C, D). Data are means + SEM pooled from $\geq 2$ independent experiments, each dot is a separate mouse, $p$ values from Kruskal Wallis test with Dunn's multiple comparison correction. 


\section{DISCUSSION:}

Tuft cells are sentinel airway epithelial cells positioned to sense inhaled antigens with apical tuft-like projections extending into airway lumen (44). The functions of these unique cells were obscure until they were firmly established as initiators of type 2 immunity in the intestine. Our results implicate them as important drivers of aeroallergen-initiated type 2 inflammation in the airways. Tuft cells are the dominant source of IL-25 in the airways, and IL-25 signaling is required for the development of type 2 inflammation in the lung after Alternaria inhalation (20, 21). Here, we demonstrate that the tuft cell-derived mediators $\mathrm{LTC}_{4}$ and IL-25 synergize to promote type 2 inflammation in the lung. Although signaling through $\mathrm{CysLT}_{1} \mathrm{R}$ drives tissue eosinophilia, signaling through both $\mathrm{CysLT}_{1} \mathrm{R}$ and $\mathrm{CysLT}_{2} \mathrm{R}$ - the latter resistant to available pharmacotherapy - is required for the full synergistic effect of $\mathrm{LTC}_{4}$ and IL-25 on type 2 lung inflammation. Finally, CysLT production by tuft cells in response to the aeroallergen Alternaria drives early eosinophilia, lymph node hyperplasia, and innate immune cell activation. These findings uncover how inflammatory lipids, previously not known to be produced by the epithelium, synergize with epithelial 'alarmin' cytokines to drive cascades of type 2 inflammation in response to inhaled aeroallergens.

Tuft cells in the upper and lower airways have gained recognition as sensors of bitter tasting agonists and bacterial compounds (45-47), formylated bacterial peptides (48) and ATP (16, 45, 49, 50). ATP signaling through the $\mathrm{P} 2 \mathrm{Y} 2$ receptor in tuft cells is engaged by the aeroallergen Alternaria, leading to generation of CysLTs (16). Consistent with that mechanism, tuft celldeficient Pou $23^{--}$mice have reduced Alternaria-triggered CysLT generation and reduced airway eosinophilia (16). Here, we used a mouse with a tuft cell-targeted deletion of $L t c 4 s$, the terminal CysLT biosynthetic enzyme, to ablate the CysLT pathway specifically in these cells. Deletion of 
$L t c 4 s$ did not alter the homeostatic transcriptional profile of airway tuft cells or their ability to respond to ATP and allergen activation with generation of the lipid mediator $\mathrm{PGD}_{2}$, and did not alter their capacity to generate IL-25. Tuft cell-specific deletion of CysLT production impaired both early Alternaria-induced eosinophilia in the lung and the systemic response to this aeroallergen. Surprisingly, the reduction in airway inflammation was not further reduced in tuft cell deficient Pou $23^{-/-}$mice (which lack tuft cell-derived CysLTs and IL-25) compared to Chat ${ }^{C r e} L t c 4 s^{f l f l}$ mice. This appeared inconsistent with our previous findings that IL-25 signaling is required for the full development of lung inflammation triggered by Alternaria (20). We considered that this might be due to direct activation of tuft cells by IL-25 through IL17RB for CysLT generation. However, high dose IL-25 induced lung inflammation, and the synergy of low dose IL-25 and $\mathrm{LTC}_{4}$ were not diminished in mice with disrupted CysLT generation. This suggests that $\mathrm{LTC}_{4}$ and IL-25 are likely generated concurrently when tuft cells are activated by allergens. The level of IL-25 in this model is likely too low to detect in biological fluids but sufficient to synergize with the high levels of CysLT generated in response to Alternaria (6, 51). Thus, in this Alternaria-initiated airway inflammation model, IL-25 signaling requires the presence of CysLTs to trigger ILC2 activation, lung eosinophil recruitment, and DC activation and migration to the lymph nodes. This system of lipid mediator synergy with IL-25 can be engaged to promote type 2 inflammation and could be engaged when the epithelial cytokine IL25 is produced at low levels.

Consistent with the hypothesis that CysLTs might be required for optimal IL-25 signaling in allergic inflammation, we found that $\mathrm{LTC}_{4}$ can render low dose non-pathogenic IL-25 into a strong inducer of type 2 airway immune responses. Low-dose IL-25 was insufficient to induce lung inflammation but synergized with $\mathrm{LTC}_{4}$ to activate ILC2s and DCs and to potently induce 
type 2 eosinophilic lung inflammation. Neuromedin U similarly synergizes with IL-25 to greatly potentiate type 2 inflammation (9). These studies demonstrate that several mediators derived from tissue resident cells promote the effect of IL-25 on type 2 immunity and suggest that IL-25 effects are tightly regulated, likely to limit their pathogenetic potential. IL-25 and $\mathrm{LTC}_{4}$ have an additive effect on intestinal ILC2 activation in vitro (32) but their effect in vivo far exceeds the effect of either mediator alone. Beyond ILC2s, several immune cell subsets were activated and increased in numbers, including DCs, with a specific increase in CD301b ${ }^{+}$DCs and CD4 T cells. Finally, IL-4, IL-5, IL-13 and IL-6 were potently induced by IL-25 + LTC 4 , with moderate induction of TNF- $\alpha$ and no effect on interferon $\gamma$ or IL-17 type cytokines. Thus, this lipid mediator/epithelial cytokine synergy induces activation of several immune cell types and potently skews tissue inflammation towards type 2 immune response.

Our findings of receptor requirements for both $\mathrm{CysLT}_{1} \mathrm{R}$ and $\mathrm{CysLT}_{2} \mathrm{R}$ signaling for the development of type 2 inflammation in response to LTC $4+$ IL 25 highlight the complexity of the CysLT signaling system. CysLT $\mathrm{T}_{1} \mathrm{R}$ and $\mathrm{CysLT}_{2} \mathrm{R}$ are broadly expressed in hemopoietic cells of the innate (macrophages, monocytes, eosinophils, basophils, mast cells, DCs) and adaptive (T cells, B cells) immune system, suggesting multiple sites of possible cooperative functions in inflammation (52). Among the innate immune cells specifically activated by IL-25 $+\mathrm{LTC}_{4}$, ILC2s and DCs express both CysLT ${ }_{1} \mathrm{R}$ and $\mathrm{CysLT}_{2} \mathrm{R}(5,7,53,54)$, and both cell types also express IL17RB $(9,34)$. Despite the reported broad expression of both CysLT receptors, here we find that $\mathrm{CysLT}_{1} \mathrm{R}$ is the dominant receptor mediating lung eosinophilia and DC recruitment in response to $\mathrm{LTC}_{4}+\mathrm{IL}-25$. This is consistent with the major effect of CysLT $\mathrm{T}_{1} \mathrm{R}$ in mediating the synergy of IL-33 and LTC 4 on lung eosinophilia (7) and lung ILC2 activation (5, 7). While the potentiation effect of $\mathrm{LTC}_{4}$ on IL-33-induced ILC2 activation and lung eosinophilia is 
independent of $\mathrm{CysLT}_{2} \mathrm{R}$ signaling, we find that both $\mathrm{CysLT}_{1} \mathrm{R}$ and $\mathrm{CysLT}_{2} \mathrm{R}$ are required for induction of type 2 cytokines in the lung. This is consistent with the effect of $\mathrm{LTC}_{4}$ on eosinophilic lung inflammation in mice sensitized with ovalbumin. In this model, $\mathrm{LTC}_{4}$ induces ILC2 expansion and type 2 cytokines IL-5 and IL-13, an effect dependent on both CysLT 1 R and $\mathrm{CyLT}_{2} \mathrm{R}(30,55)$. Thus, the effect of $\mathrm{LTC}_{4}$ likely depends on the specific cellular milieu in the vicinity of the $\mathrm{LTC}_{4}$ source. Interestingly, we find that both $\mathrm{CysLT}_{1} \mathrm{R}$ and $\mathrm{CysLT}_{2} \mathrm{R}$ are required for the expansion of the inflammatory ILC2 subset of $\mathrm{KLRG} 1^{+} \mathrm{ICOS}^{+} \mathrm{ILC} 2 \mathrm{~s}$. This specific subset of "inflammatory" ILC2s was previously described as specifically induced by high dose IL-25 and requires signaling through $\operatorname{IL} 17 \mathrm{RB}(9,34)$. Here, we observe that $\mathrm{LTC}_{4}$ facilitates the induction of these inflammatory ILC2s. The fact that CysLT receptor deletion sharply diminishes their numbers in the lung is consistent with their dependence on IL17RB signaling, and with the exquisite requirements for physiologically generated IL-25 to synergize with CysLTs. Thus, the in vivo selectivity of $\mathrm{LTC}_{4}$ might differ depending on the tissue distribution of the cellular source, the epithelial cytokines generated in concert with these lipid mediators, and the frequency of CysLT receptor expressing cells and their proximity to the ligand source $(53,56-$ 58).

Alternaria and house dust mite inhalation are associated with an increase in the frequency of tracheal tuft cells dependent on endogenous CysLTs and only partially dependent on Stat6 signaling (20). Here we find that mice with tuft cell deletion of Ltc4s phenocopy the germline $L t c 4 s^{-/-}$mice for the absence of tuft cell expansion, suggesting that these cells are a major contributor to the endogenous CysLTs needed for this function. Previously, we had shown that exogenous $\mathrm{LTE}_{4}$, the most stable CysLT, increases the frequency of tracheal tuft cells in a Stat6independent manner mediated by Cysltr3 (20). suggesting a CysLT-dependent mechanism of 
epithelial remodeling independent of classical IL-13-driven mechanisms. Now, we find that tuft cells in the trachea are not induced in our pharmacologic model despite strong induction of lung IL-13 and concomitant goblet cell metaplasia in the lung. This supports the observation that tracheal tuft cell expansion in the airways is not directly dependent on IL-13, despite the dominant role of this cytokine in goblet cell metaplasia in the airways and in intestinal tuft cell expansion. The dichotomy of IL-13-dependent goblet cell metaplasia and IL-13-independent tracheal tuft cell expansion - even in the presence of $\mathrm{LTC}_{4}$ - further highlights the unique role of each member of the CysLT family, where $\mathrm{LTC}_{4}$ acts in concert with epithelial cytokines to induce robust type 2 inflammation, while $\mathrm{LTE}_{4}$ has an independent effect on tracheal remodeling for tuft cell expansion (20).

While the pharmacological synergy of IL-25 with $\mathrm{LTC}_{4}$ for type 2 immunity suggest that both are central mediators produced by tuft cells, we cannot exclude the possibility that $\mathrm{LTC}_{4}$ from tuft cells might have broader effects on immune responses beyond this specific interaction. Tuft cells are also prominent sources of acetylcholine, which can be generated in response to formylated peptides (48). Recent studies suggest that a population of Chat-expressing ILC2 that also expresses cholinergic receptors is specifically induced by Alternaria in the lung (39). Thus, an interaction between acetylcholine and CysLTs might further augment the activation of ILC2s. Interestingly, although both Chat and $L t c 4 s$ are widely expressed in diverse immune subsets, we find that only tuft cells uniquely co-express both markers, further expanding the possibility of a functional importance of this co-localization.

In summary, our data provide evidence of a system of allergen-triggered responses in the airways. This system is initiated by activation of specialized airway tuft cells, which then generate potent lipid mediators that trigger the innate phase of type 2 inflammation via 
downstream activation of innate immune cells. Two mediators generated by tuft cells $-\mathrm{LTC}_{4}$ and IL-25 - cooperate for an enhancement of the inflammatory response. Notably, in mouse models, the most dramatic increase in airway tuft cell numbers is found in the recovery phase of influenza infection (59). In human airway diseases, CysLTs are found in the BAL of infants with RSV bronchiolitis (60-62) and IL-25 is induced by viral exacerbations of asthma (63). Beyond allergen recognition, this system may also play decisive roles in other airway diseases associated with IL-25 and CysLT production. 


\section{MATERIALS AND METHODS}

\section{Study design}

The aims of this study were to define the role of two of the major tuft cell-derived mediators $-\mathrm{LTC}_{4}$ and IL-25 in driving type 2 inflammation in the airways. We used a pharmacologic model to evaluate the lung inflammation induced by $\mathrm{LTC}_{4}$ or IL-25 alone or in combination. Using mice with receptor-specific deletion for each CysLT receptor, we identified the two receptors responsible for mediating this response. We then developed and characterized transcriptionally a new mouse with tuft cell-specific deletion of $\mathrm{LTC}_{4}$ generation Chat ${ }^{C r e} L t c 4 s^{f l f l}$. We then used this mouse to specifically characterize the dependence on tuft cellderived CysLTs in a mouse model of allergen-induced inflammation.

\section{Experimental Models and Mice}

ChAT $^{\mathrm{BAC}}$-eGFP [B6.Cg-Tg(RP23-268 L19-EGFP)2Mik/J], ChAT-IRES-Cre::frt-neo-frt [Chat ${ }^{\text {tm2(cre)Lowl }}$, C57BL/6 and C57BL/6N-Cysltr1tm1 1 knn/J mice were purchased from Jackson Laboratories (Bar Harbor, ME). $\mathrm{Ltc}_{4} \mathrm{~s}^{-1-}$ mice were generated on a $129 \mathrm{~Sv}$ background and backcrossed for 15 generations onto the C57BL/6 background (64). CysLT $_{2-}\left(\right.$ Cysltr2 $\left.2^{-/-}\right)$and $\mathrm{CysLT}_{3}$-receptor gene-knockout mice $\left(\mathrm{Oxgr1}^{-/}\right.$or $\left.\mathrm{Cysltr}^{-/-}\right)$were generated on a C57BL/6 and as previously described $(43,65)$. Mcpt5/DTA mice were generated by crossing mice with mast cell-specific expression of Cre recombinase (66) on a C57BL/6 background with ROSAdiphtheria toxin- $\alpha$ mice (B6.129P2-Gt(ROSA)26Sortm1(DTA)Lky/J from Jackson Laboratories). Pou $23^{-/-}$mice were generated as described previously (67) and compared to C57BL/6 mice bred in-house (originally from Charles River Laboratories, Wilmington, MA). $L t c 4 s^{f l f l}$ mice were provided by Dr. J. Boyce and generated by Ingenious Lab. B6. $L t c 4 s^{f l f l}$ mice with loxP sites flanking the 1 st exon of $L t c 4 s$ were generated by homologous gene targeting in C57BL/6 embryonic stem cells. Targeted iTL BF1 (C57BL/6 FLP) embryonic stem cells were microinjected into Balb/c blastocysts. Resulting chimeras with a high percentage black coat color were mated to C57BL/6 WT mice to generate Germline Neo Deleted mice. Homozygous Ltc $4 s^{f l f l}$ mice were then crossed with Chat ${ }^{C r e}$ mice to generate double heterozygous mice $\left(C h a t^{C r e+} L t c 4 s^{f l}\right)$, which were further mated with $L t c 4 s^{f l f l}$ mice to generate two genotypes of mice: $L t c 4 s^{f l f l}$ and $C h a t^{C r e+} L t c 4 s^{f l f l}$ and used as littermate controls of each other. 
All animals were maintained in a specific pathogen-free facility at the Brigham and Women's Hospital; litter was weaned between 19-28 days old. All experiments were performed during the day. Pooled results include both male and female mice. The use of mice for these studies was in accordance with review and approval by the Animal Care and Use Committee of Brigham and Women's Hospital. Mice were randomly assigned to treatment groups after matching for sex, age and genotype.

\section{Aeroallergen, IL-25 and $\mathrm{LTC}_{4}$ Challenge Protocols}

Mice were anesthetized with an intraperitoneal injection of ketamine $(10 \mathrm{mg} / \mathrm{kg})$ and xylazine $(20 \mathrm{mg} / \mathrm{kg})$ for full sedation and received a single intranasal (i.n.) application of pharmacologic agonists or allergen dissolved in $20 \mu \mathrm{l}$ PBS. For low-dose IL-25 and LTC 4 + IL25 synergy experiments, mice were treated intranasally with either $1.6 \mathrm{mmol}$ of $\mathrm{LTC}_{4}$, or $100 \mathrm{ng}$ IL-25, or combination of $100 \mathrm{ng}$ IL25 and $1.6 \mathrm{mmol}$ of $\mathrm{LTC}_{4}$. $\mathrm{LTC}_{4}$ was stored in ethanol; the ethanol was evaporated and $\mathrm{LTC}_{4}$ was reconstituted in PBS for immediate application. In another set of experiments, mice were given $500 \mathrm{ng}$ IL-25 intranasally. LTC 4 , IL-25 and the combination of $\mathrm{LTC}_{4}$ and IL-25 were administered in $20 \mu \mathrm{l}$ volume daily for three consecutive days. Tissues were harvested 48 hours after the last intranasal administration.

For allergen challenge experiments, mice were give a single intranasal inhalation of 30 $\mu \mathrm{g}$ of Alternaria alternata culture filtrate. Mice were euthanized with ketamine overdose at 1 hour for nasal lavage, at 24 hours for BAL or mediastinal lymph node and at 72 hours for lung and tracheal harvesting.

\section{Nasal and BAL lavage}

For nasal lavage, mice were euthanized 1 hour after the i.n. challenge, and the lavages were obtained through a small incision in the trachea. The nasal lavage was performed with 200 $\mu 1$ of PBS and the fluid proteins were precipitated with ice cold acetone. After high-speed centrifugation, the supernatant was used for CysLT and $\mathrm{PGD}_{2}$ measurements.

BAL for assessment of inflammation was collected by repetitive $(n=3)$ injection and aspiration of the lungs with $0.75 \mathrm{ml}$ of PBS with $1 \mathrm{mM}$ EDTA through a tracheal opening. The BAL fluid was centrifuged at $500 \mathrm{~g}$ for $5 \mathrm{~min}$ and the supernatant was discarded. Cell pellets were resuspended in $0.2 \mathrm{ml}$ of PBS, and the total cells were counted manually under a 
microscope with a hemocytometer. For the differential cell counts of macrophages, neutrophils, and eosinophils, the BAL cells were cytospun onto fresh labeled glass slides at $500 \mathrm{rpm}$ for 5 min. Air-dried slides were further stained using Diff-Quick stain kit. Cell types in a total of 200 cells were identified by morphologic criteria (53) and differential cell counts were performed under microscope.

\section{$\underline{\text { Single cell suspensions preparation }}$}

For single-cell preparations of the nasal mucosa, each euthanized mouse was decapitated, and the snout was released of surrounding bones and tissues. The nasal mucosa was exposed dorsally by cutting nasal bone located on the calvarium and ventrally by incising along the palate.

In a set of experiments with ChAT-eGFP mice used for RNAseq, the olfactory mucosa overlying the ethmoturbinates, dorsal nasal meatus and caudal half of the septum were separated from respiratory mucosa, comprised of nasal conchae and the ventral half of the septum, containing the vomeronasal organ. For all other genotypes, the whole snout, including the olfactory and respiratory areas, was processed together.

The nasal mucosa was incubated in pre-warmed PBS solution with dispase $(16 \mathrm{U} / \mathrm{ml})$ and deoxyribonuclease I (DNase I; $20 \mu \mathrm{g} / \mathrm{ml}$ ) for 30 to $40 \mathrm{~min}$ at room temperature on a rotating shaker at $220 \mathrm{rpm}$. Dispase activity was reduced with Dulbecco's modified Eagle's medium (DMEM) and 5\% fetal bovine serum (FBS). The separated nasal mucosa was incubated in Tyrode's Solution with bicarbonate, HEPES, $0.25 \% \mathrm{BSA}$, without $\mathrm{Ca}^{2+}$, with added $48 \mathrm{U} / \mathrm{mg}$ of papain, $25 \mathrm{mg} / \mathrm{mL}$ L-cysteine and $20 \mu \mathrm{g} / \mathrm{mL}$ DNAse I for $40 \mathrm{~min}$ at $37^{\circ} \mathrm{C}$ on a rotating shaker (68). Papain digestion was terminated with Tyrode's Solution with HEPES and $\mathrm{Ca}^{2+}$ and with 2 $\mu \mathrm{l} / \mathrm{mL}$ leupeptin $(5 \mathrm{mg} / \mathrm{ml})$. The digested tissue was vortexed for $20-30 \mathrm{sec}$, triturated thoroughly with an 18-gauge needle followed by a 21-gauge needle, passed through a $100 \mu \mathrm{m}$ filter, and washed with FACS buffer (based on Hank's Balanced Salt Solution (HBSS) without $\mathrm{Ca}^{2+}$, with added $2 \%$ FBS and 2 mM EDTA).

To isolate nasal hematopoietic cells for RNAseq, the snout was harvested as described above. The freshly isolated nasal mucosa was enzymatically dissociated with a PBS-based solution containing collagenase $(650 \mathrm{U} / \mathrm{ml})$, dispase $(16 \mathrm{U} / \mathrm{ml})$, and DNase I for $30 \mathrm{mins}$ at $37^{\circ} \mathrm{C}$ on a rotating shaker. The digestion was terminated by addition of $1 \mathrm{ml}$ of cold DMEM with 5\% 
FBS. Digested mucosal samples were further vortexed, triturated and processed similarly to epithelial cells described previously.

For evaluation of lung inflammation, lungs were flushed with $10 \mathrm{ml}$ of cold HBSS until they appeared white in color. The right lower lobe was removed, physically dissociated with a gentle MACS Dissociator in $10 \mathrm{ml}$ of RPMI 1640 containing 10\% FBS, followed by digestion with collagenase $(500 \mathrm{U} / \mathrm{ml})$, dispase $(6.6 \mathrm{U} / \mathrm{ml})$ and DNase I $(20 \mu \mathrm{g} / \mathrm{mL})$ in RPMI 1640 with $5 \% \mathrm{FCS}$ at $37^{\circ} \mathrm{C}$ for $30 \mathrm{~min}$ with agitation at $200 \mathrm{rpm}$. The digestion was terminated by adding $10 \mathrm{ml}$ of cold RPMI 1640 with 10\% FBS. Cell suspensions were washed with FACS buffer and prepared for analysis by flow cytometry.

To isolate immune cells, harvested lung draining mediastinal lymph nodes were digested in PBS solution containing collagenase $(100 \mathrm{U} / \mathrm{ml})$ and DNase I $(20 \mu \mathrm{g} / \mathrm{ml})$ for $30 \mathrm{mins}$ at $37^{\circ} \mathrm{C}$. The cell suspension was further triturated with a pipette tip, filtered, washed and further stained for flow cytometry.

\section{Flow cytometry and sorting}

Before staining the cells, the nonspecific monoclonal antibody uptake was blocked with CD16/32 for at least $30 \mathrm{~min}$. All samples were FSC-A/SSC-A gated to exclude debris, SSCH/SSC-W and FSC-H/SSC-W gated to select single cells. Propidium iodide (PI) was used as a dead cell exclusion marker for samples submitted for sorting, while Hoechst was used for the same purpose in FACS analysis. The nasal epithelial cells were stained using monoclonal antibodies against CD45 and EpCAM for $40 \mathrm{~min}$, followed by dead cell exclusion before sorting. Cells from ChAT-eGFP mice were collected in two subsets: tuft cells, identified as EpCAM ${ }^{\text {high }}$ $\mathrm{GFP}^{+}$cells (Fig. S3A), and other epithelial cells that were EpCAM ${ }^{\text {high }} \mathrm{GFP}^{-}(6)$. The cells were additionally gated as $\mathrm{FSC}^{\text {low }} \mathrm{SSC}^{\text {low }}$, and $\mathrm{EpCAM}^{\text {high }} \mathrm{GFP}^{+} \mathrm{FSC}^{\text {low }} \mathrm{SSC}^{\text {low }}$ cells were collected from olfactory epithelium, while EpCAM ${ }^{\text {high }} \mathrm{GFP}^{+} \mathrm{FSC}^{\text {high }} \mathrm{SSC}^{\text {high }}$ represented tuft cells from respiratory mucosa.

Epithelial cells from $L t c 4 S^{f l f l}$ and Chat ${ }^{\mathrm{Cre}} L t c 4 S^{f l f l}$ mice were collected based on their expression of CD45 and three populations of cells were submitted for RNAseq (Fig. S3B). These populations were EpCAM ${ }^{\text {high }} \mathrm{CD} 45^{\text {low }} \mathrm{FSC}^{\text {low }} \mathrm{SSC}^{\text {low }}, \mathrm{EpCAM}^{\text {high }} \mathrm{CD} 45^{\text {neg }} \mathrm{FSC}^{\text {low }} \mathrm{SSC}^{\text {low }}$, and

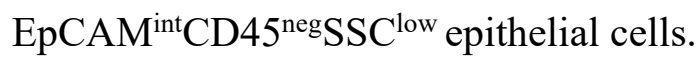

DCs were defined as $\mathrm{CD}_{4} 5^{+} \mathrm{CD} 11 \mathrm{~b}^{+}$SiglecF $^{-} \mathrm{CD} 11 \mathrm{c}^{+} \mathrm{MHCII}^{+}$cells, and macrophages 
were identified as $\mathrm{CD}_{4} 5^{+} \mathrm{CD} 11 \mathrm{~b}^{+}$SiglecF ${ }^{+} \mathrm{CD} 11 \mathrm{c}^{+}$cells after excluding $\mathrm{CD} 19$ and $\mathrm{TCR} \beta^{+}$cells. (Fig. S4C).

To identify lung ILC2s among CD45 ${ }^{+}$cells, lineage-positive cells were excluded using monoclonal antibodies against CD19, CD8, GR1, Fcer1, NK1.1, CD11c, CD11b, TCR $\beta$, TCR $\gamma \delta$, TER119 and CD4. ILC2 cells were identified as lin- Thy $1.2^{+}$cells with low forward and side scatter (Fig. S1B). Lung DCs were defined as $\mathrm{CD}_{4} 5^{+}$SiglecF $^{-} \mathrm{CD} 11 \mathrm{c}^{+} \mathrm{MHCII}^{+}$cells and further differentiated based on their expression of CD301b and CD11b. Macrophages were identified as

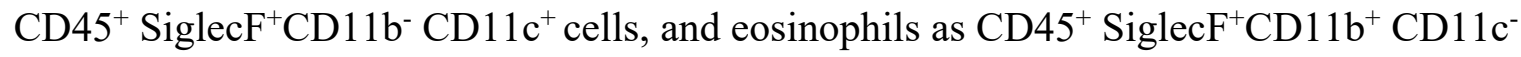
$\mathrm{SSC}^{\text {high }}$ after excluding CD19 and TCR $\beta^{+}$cells

In lymph nodes, $\mathrm{T}$ cells were identified as $\mathrm{CD} 8^{+}$and $\mathrm{CD} 4^{+}$and $\mathrm{B}$ cells were distinguished based on their expression of B220.

\section{Ex vivo stimulation of nasal tuft cells}

Sorted EpCAM ${ }^{\text {high }} \mathrm{CD} 45^{\text {low }} \mathrm{FSC}^{\text {low }} \mathrm{SSC}^{\text {low }}$ cells from Chat ${ }^{\text {Cre }}, L t c 4 \mathrm{~s}^{\text {flfll }}$ and $C h A T^{C r e} L t c 4 s^{f l f l}$ mice were plated in DMEM-based EpC proliferation media, which includes DMEM/F-12, 5\% Nu-Serum, $100 \mu \mathrm{g} / \mathrm{mL}$ Penicillin-Streptomycin (Gibco) and 0.25 $\mu \mathrm{g} / \mathrm{ml}$ Amphotericin B. Sorted CD45 $5^{+}$cells from $L t c 4 s^{f l f l}$ and Chat ${ }^{C r e} L t c 4 s^{f l f l}$ mice were reconstituted in R10 media (RPMI medium 1640 containing 10\% (vol/vol) FBS, 2 mM Lglutamine, $0.1 \mathrm{mM}$ nonessential amino acids, penicillin (100 units $/ \mathrm{ml}$ ), streptomycin (100 $\mu \mathrm{g} / \mathrm{ml})$. The cells were plated into $96-w e l l$ culture plates at a concentration of $400,000 \mathrm{cells} / \mathrm{ml}$ in $200 \mu \mathrm{L}$ of media per well for epithelial cells and $1.2 \times 10^{6}-2.3 \times 10^{6}$ cells $/ 1 \mathrm{ml}$ in $200 \mu \mathrm{L}$ for CD $45^{+}$ cells. The cells were rested overnight and stimulated with $1 \mathrm{mM} \mathrm{A23187} \mathrm{or} 0.5 \mathrm{mM} \mathrm{ATP} \gamma \mathrm{S}$ in $50 \mu \mathrm{l}$ of $\mathrm{HBSS}$ with $\mathrm{Ca}^{2+}$ and $\mathrm{Mg}^{2+}$ for $30 \mathrm{~min}$. After stimulation, the plate was centrifuged at $350 \times \mathrm{g}$ for $5 \mathrm{~min}$ at $4{ }^{\circ} \mathrm{C}$, and the supernatants were retained for assays of CysLTs and $\mathrm{PGD}_{2}$.

\section{$\underline{\text { CysLT } \text { and } P G D_{2}} \underline{\text { detection }}$}

CysLT and $\mathrm{PGD}_{2}$ generation in the supernatants of tuft cells, CD45 ${ }^{+}$sorted cells, and acetone-precipitated nasal lavage fluid were measured by commercially available enzyme ELISAs according to the manufacturer's protocol (both kits from Cayman). The assays are based on competition between CysLTs/ $\mathrm{PGD}_{2}$ and CysLT-acetylcholinesterase/ PGD2acetylcholinesterase conjugate for a limited amount of CysLT/PGD 2 ELISA Monoclonal 
Antibody. The lower limit of detection for CysLT ELISA was $60 \mathrm{pg} / \mathrm{mL}$ and the following reported reactivity: Leukotriene $\mathrm{C}_{4}(100 \%)$, Leukotriene $\mathrm{D}_{4}(100 \%)$, Leukotriene $\mathrm{E}_{4}(79 \%), 5,6-$ DiHETE (3.7\%), Leukotriene $\mathrm{B}_{4}(1.3 \%), 5(\mathrm{~S})$-HETE (0.04\%), Arachidonic Acid $(<0.01 \%)$. The lower limit of detection for $\mathrm{PGD}_{2}$ ELISA was $19.5 \mathrm{pg} / \mathrm{mL}$ and the following reported reactivity: Prostaglandin $\mathrm{D}_{2}(100 \%)$, Prostaglandin $\mathrm{F}_{2 \alpha}(92.4 \%)$, Prostaglandin $\mathrm{J}_{2}(21.6 \%)$, Prostaglandin $\mathrm{E}_{2}$ (2.86\%), Thromboxane $\mathrm{B}_{2}(2.54 \%), 11 \beta$-Prostaglandin $\mathrm{F}_{2 \alpha}(1.99 \%)$, 8-iso Prostaglandin $\mathrm{F}_{2 \alpha}$ (1.90\%), Prostaglandin $\mathrm{A}_{2}(0.72 \%), 12(\mathrm{~S})$-HHTrE $(0.16 \%)$, 6-keto Prostaglandin $\mathrm{F}_{1 \alpha}(0.05 \%)$, (13,14-dihydro-15-keto Prostaglandin $\left.\mathrm{D}_{2}\right)$ 0.02\%, Arachidonic Acid ( $\left.<0.01 \%\right)$, Leukotriene $\mathrm{D}_{4}$ $(<0.01 \%)$, tetranor-PGDM $(<0.01 \%)$, tetranor-PGEM $(<0.01 \%)$, tetranor-PGFM $<0.01 \%)$ and tetranor-PGJM $(<0.01 \%)$.

\section{Cytokine detection in the lung}

For protein extraction, the frozen lobes of the right lungs were mechanically homogenized in $300 \mu \mathrm{l}$ of T-PER protein extraction buffer supplemented with appropriate amount of protease inhibitor cocktail (cOmplete ${ }^{\mathrm{TM}}$, Mini Protease Inhibitor Cocktail, Sigma Aldrich; $10 \mathrm{~mL}$ T-Per buffer/1 tablet). The suspensions were spun, and the supernatants were collected. The protein concentration was measured with commercially available bicinchonic acid (BCA) protein assay kit (ThermoFisher) according to manufacturer's instructions.

The cytokine concentrations were measured with LEGENDplex T-helper Cytokine Panel (Biolegend) in V-bottom plates, following the manufacturer's instructions. In brief, supernatants were incubated for 2 hours with fluorescence-encoded beads, differentiated by size and internal fluorescence intensities to detect 12 cytokines. The cytokine panel included IFN- $\gamma$, IL-5, TNF- $\alpha$, IL-2, IL-6, IL-4, IL-10, IL-9, IL-17A, IL-17F, IL-22, IL-13 After washing, a biotinylated detection antibody cocktail was added, followed by incubation with streptavidin-phycoerythrin. Fluorescent signal intensities were then measured on 5-Laser BD FACSAria Fusion.

\section{Histochemistry and quantitative assessment of goblet cell numbers}

For histochemical evaluation, the left lung was embedded in glycolmethacrylate. Tissue sections, $2.5 \mu \mathrm{m}$ thick, were assessed by PAS for quantitation of mucin-containing goblet cells and by Congo red reactivity for quantitation of eosinophil recruitment. Slides were counterstained with hematoxylin for general morphologic examination. All histologic 
assessments were done in a blinded fashion by a single investigator.

The number of PAS-reactive cells for each animal was enumerated from 3-6 10-20x digital photographs spanning 2-13 mm basement membrane over the 4 coronal sections. This area was divided by the length of basement membrane to define the average thickness of the submucosal space.

\section{Confocal microscopy of whole tracheal mounts and quantitative assessment of tuft cells}

The harvested tracheas were fixed with 4\% PFA, washed with PBS and permeabilized in a PBSbased blocking buffer containing $0.1 \%$ Triton $\mathrm{X}-100,0.1 \%$ saponin, $3 \%$ bovine serum albumin, and 3\% normal donkey serum for at least 3 hours. The tracheas were further incubated with primary rabbit anti-DCLK1 antibody added to the permeabilizing solution at $4^{\circ} \mathrm{C}$ for 48 to 72 hours. The samples were then washed with PBS containing $0.1 \%$ Triton X-100 for 3 hours and transferred to PBS containing donkey anti-rabbit secondary antibody, Alexa Fluor Plus 594 and Hoechst 33342 for nuclear stain. Tracheas were longitudinally split into two halves and embedded with the epithelial surface facing upward using a glycerol-based cover slipping solution. Images were acquired at the Brigham and Women's Hospital Confocal Microscopy Core Facility using the Zeiss LSM 800 with Airyscan confocal system on a Zeiss Axio Observer Z1 inverted microscope with 10× Zeiss [0.30 numerical aperture (NA)], 20× Zeiss ( $0.8 \mathrm{NA})$, and a $63 \times$ Zeiss oil (1.4 NA) objectives. The number of tuft cells for each animal was enumerated from 6 to 8 photographs corresponding to $0.6-1 \mathrm{~mm}^{2}$ taken from the same areas of each trachea starting at the distal end in proximity to the carina. The total number of DCLK1 immunoreactive cells (ranging from 131 to 205 tuft cells in unchallenged mice to 144 to 296 tuft cells in challenged mice) was divided by the area captured in the focal plane to define the number of DCLK1 ${ }^{+}$cells per square millimeter. DCLK1 immuno-reactive cells and focal plane area were evaluated using ImageJ (National Institutes of Health, Bethesda, MD). Separate images were collected for each fluorochrome and overlaid to obtain a multicolor image.

\section{Low input RNA sequencing.}

\section{Preprocessing}

BCL files were converted to merged, de-multiplexed FASTQ files using the Illumina Bcl2Fastq software pack- age v.2.17.1.14. Paired-end reads were mapped to the UCSC mm10 
mouse transcriptome using Bowtie57 with parameters '-q-phred33-quals -n 1 -e 99999999 -1 25 -I 1 -X 2000 -a -m 15 -S -p 6', which allows alignment of sequences with one mismatch. Gene expression levels were quantified as transcript-per-million (TPM) values by RSEM58 v.1.2.3 in paired-end mode. For each sample, we determined the number of genes for which at least one read was mapped, and then excluded all samples with fewer than 10,000 detected genes. Only one sample was excluded in this way. Computational pipelines for RNA seq analysis were implemented as described elsewhere $(11,24)$.

Briefly, variable genes were selected using logistic regression fit to fraction of samples in which each transcript was detected, using the log of total transcripts for each gene as a predictor. Outliers from this curve are genes that are expressed in a lower fraction of samples than would be expected given the total number of reads mapping to that gene, that is, treatment condition or state-specific genes. We used a threshold of deviance $<-0.2$, producing a set of 2307 variable genes. We restricted the expression matrix to this subset of variable genes, and took the variance stabilizing transformation $\log 2(\mathrm{TPM}+1)$ to generate the digital gene expression (DGE) matrix that was used for all downstream analysis. We performed dimensionality reduction on the DGE matrix using PCA. Values were centered and scaled before input to PCA, which was implemented using the R function 'prcomp' from the 'stats' package. The data were visualized in Fig. 3 using the first two principal components, which accounted for $29 \%$ and $10 \%$ of the variance respectively.

\section{Comparison to known tuft cell signature}

Tuft cell marker genes were derived from the 'consensus' signature defined with singlecell RNA sequencing (11). Heatmaps were generated using the 'pheatmap' R package.

\section{Correlation of nasal epithelial groups}

Pairwise Pearson correlations between all samples were calculated using the $\mathrm{R}$ function 'cor' from the 'stats' package (Fig. S3D). To identify the similarity between the putative prospectively isolated tuft cells ( $L t c 4 s^{f l f l}$ EpCAM $\left.^{\text {high }} \mathrm{CD} 45^{\text {low }}\right)$, the mean expression of each gene across the $L t c 4 s^{f l f l}$ EpCAM ${ }^{\text {high }} C D 45^{\text {low }}$ tuft cell-enriched samples, and used this as a reference signature to calculate Pearson correlations with other samples. We visualized the 
correlation of each sample to the $L t c 4 s^{f l f l}$ EpCAM ${ }^{\text {high }} C D 45^{\text {low }}$ consensus signature, grouped by sample population, and ranked these by their mean correlation.

\section{$L t c 4 s$ expression in neurons}

Expression data for mouse neuronal populations was downloaded from the Mouse Brain Atlas (http://mousebrain.org/downloads.html) and visualized using the 'ggplot2' package in R.

\section{Statistics}

Analysis was performed with GraphPad Prism software (version 8). Nonparametric twosided Mann-Whitney and unpaired T tests were used to determine significance in pairwise comparison of responses in the in vivo and ex vivo stimulation models. For experiments with $\geqq 4$ group comparisons, the overall significance was determined using a one-way ANOVA and pairwise comparison was performed with Kruskall-Wallis tests with Dunn's correction. A value of $p<0.05$ was considered significant. Sample sizes were not predetermined by statistical methods. 


\section{Tuft cell-produced cysteinyl leukotrienes and IL-25 synergistically initiate lung type 2 inflammation}

Saltanat Ualiyeva ${ }^{1 \#}$, Evan Lemire ${ }^{2 \#}$, Evelyn C. Aviles ${ }^{3}$, Amelia A. Boyd ${ }^{1}$, Caitlin Wong ${ }^{1}$, Juying Lai $^{1}$, Tao Liu ${ }^{1}$, Ichiro Matsumoto ${ }^{4}$, Nora A. Barrett ${ }^{1}$, Joshua A. Boyce ${ }^{1}$, Adam L. Haber ${ }^{2}$, and Lora G. Bankova ${ }^{1 *}$

\section{SUPPLEMENTARY MATERIALS:}

Fig. S1. LTC 4 and IL-25 synergize for airway type 2 lung inflammation.

Fig. S2. Cytokine expression profile in the lungs after intranasal challenge with $\mathrm{LTC}_{4}+\mathrm{IL}-$ 25.

Fig. S3. EpCAM ${ }^{\text {high }}$ CD45 ${ }^{\text {low }}$ cells are highly enriched for tuft cells.

Fig. S4. Chat and Ltc4s are specifically co-expressed in tuft cells.

Fig. S5. The transcriptional profile of tuft cells from $C_{h a t}{ }^{C r e} L t c 4 s^{f l f l}$ mice is unaltered.

Fig. S6. The synergy of IL-25 and LTC4 is preserved in $\mathrm{Chat}^{\mathrm{Cr}} \mathrm{Ltc4s^{flfl }}$ mice.

Fig. S7. High dose IL-25 induced inflammation is preserved in $\mathrm{Ltc}^{-/ /} \mathrm{s}^{-/}$mice.

Table 1. Materials 
A Hematoxylin and eosin
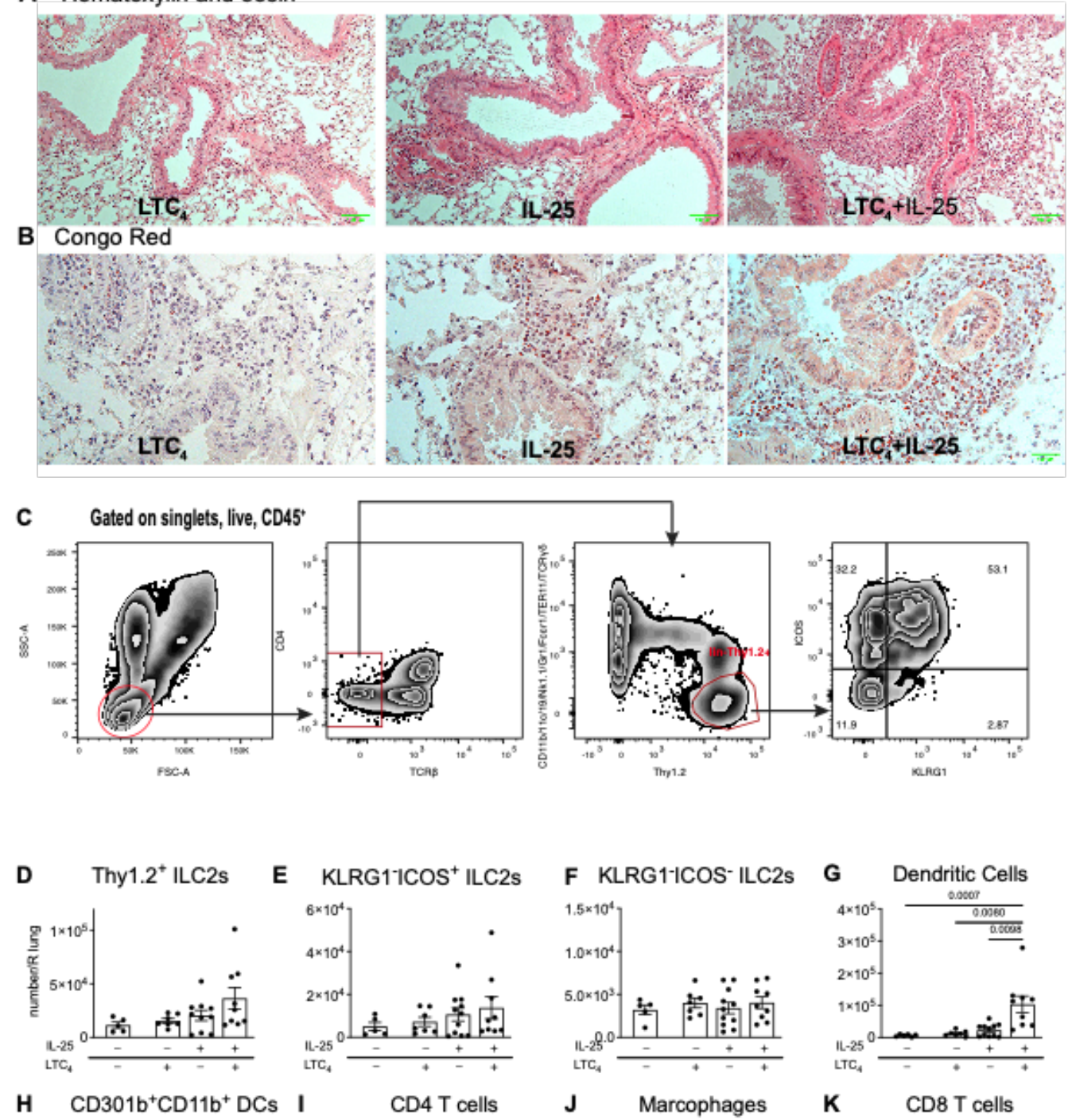

H
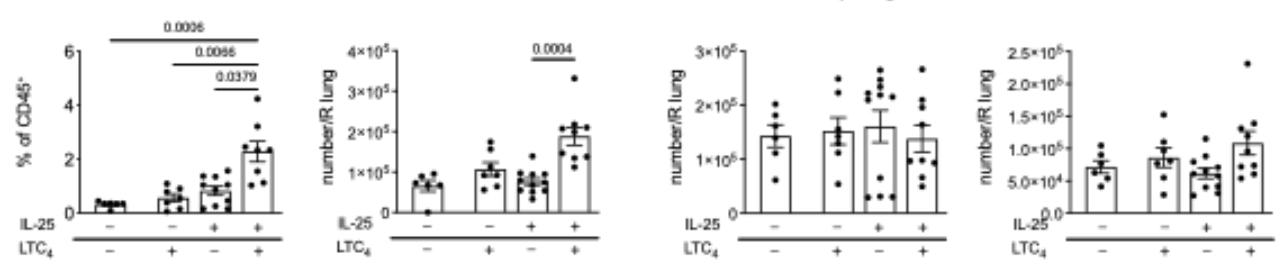

Fig. S1. LTC 4 and IL-25 synergize for airway type 2 lung inflammation.

(A) WT (C57BL/6 and $\left.L t c 4 s^{f l f f}\right)$ or Chat ${ }^{C r e} L t c 4 s^{f / f l}$ mice were given three daily inhalations of $\mathrm{LTC}_{4}(1.6$ mmol) or IL-25 (100 ng) or a combination of LTC $_{4}$ and IL-25 and assessed 2 days after the last dose. The lung inflammatory infiltrate was assessed by hematoxylin and eosin staining $(\mathbf{A})$ and eosinophils were visualized by Congo Red stain (B). (C) Gating strategy for ILC2s. (D-F) Number of all Thy1.2+ILC2s and subsets of KLRG1- ILC2s defined by FACS. (G) Total number of DCs (CD45 ${ }^{+}$B220 ${ }^{-}$SiglecF $^{-}$ $\mathrm{CD} 11 \mathrm{c}^{+} \mathrm{CD} 11 \mathrm{~b}^{+}$) and $(\mathbf{H})$ percent of CD301b $\mathrm{b}^{+}$DCs. (I-K) Numbers of CD4 T cells, macrophages and $\mathrm{CD} 8 \mathrm{~T}$ cells in the lung. Data are means \pm SEM pooled from 3 independent experiments, each dot is a mouse, $p$ values $<0.05$ indicated, Kruskal-Wallis ANOVA with Dunn's correction for multiple comparisons. 

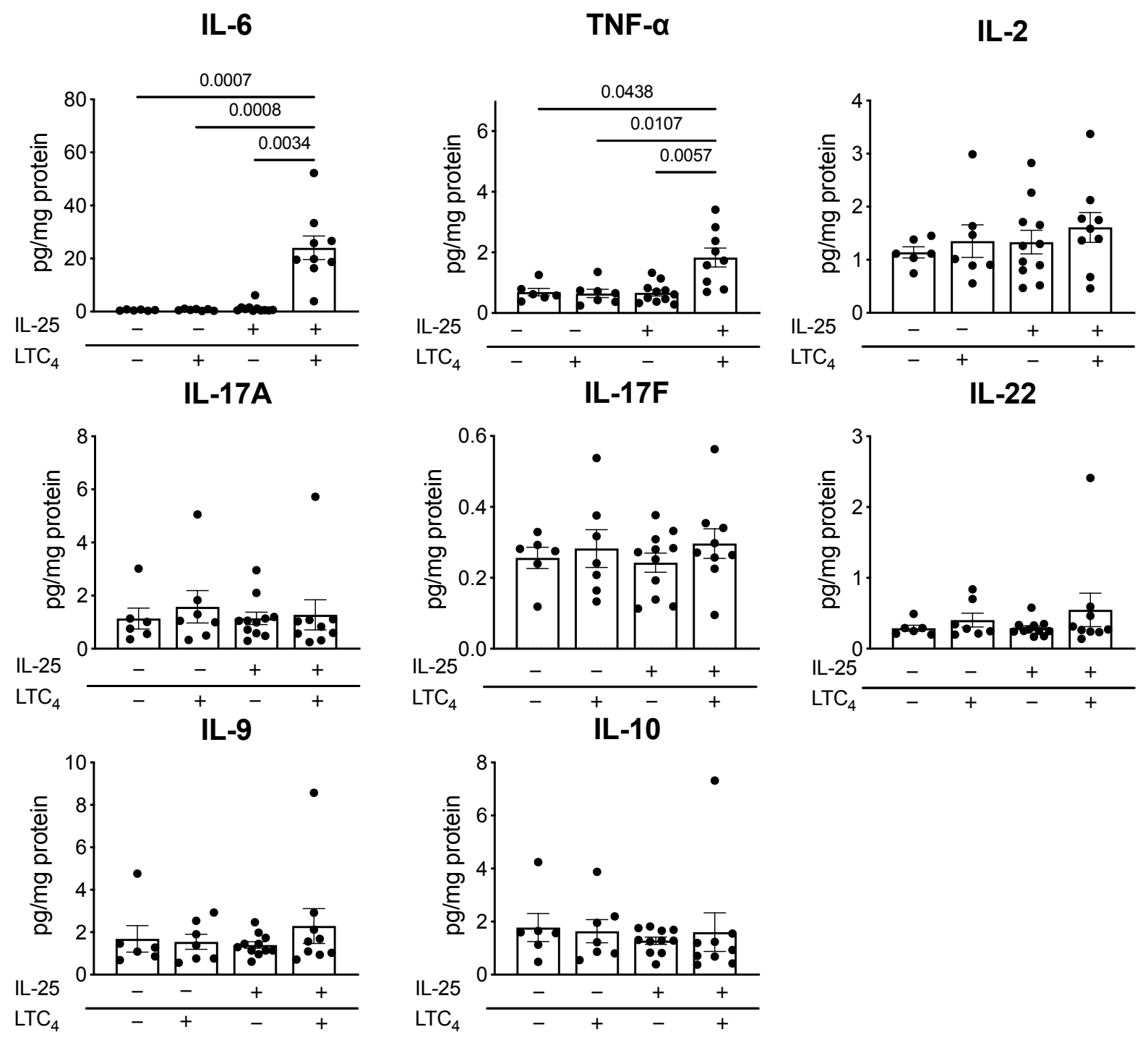

Fig. S2. Cytokine expression profile in the lungs after intranasal challenge with $\mathrm{LTC}_{4}+\mathrm{IL}-$ 25.

Lung cytokine concentration was determined by LegendPlex ELISA and expressed as pg per mg of lung protein. Data are means \pm SEM pooled from 3 independent experiments, each dot is a separate mouse, $\mathrm{p}$ values $<0.05$ indicated, Kruskal-Wallis ANOVA with Dunn's correction for multiple comparisons. 


\section{A $\quad L t c 4 s^{f f l}$ mice}

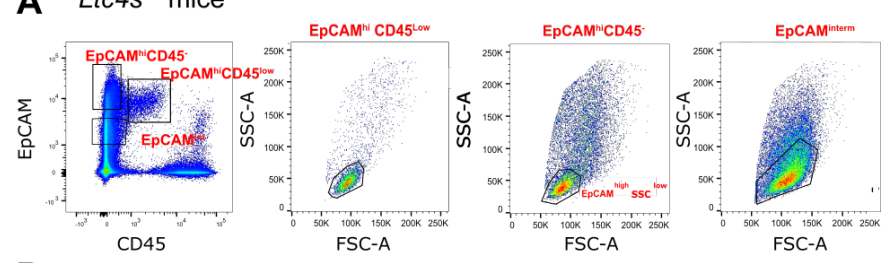

B ChAT-eGFP mice
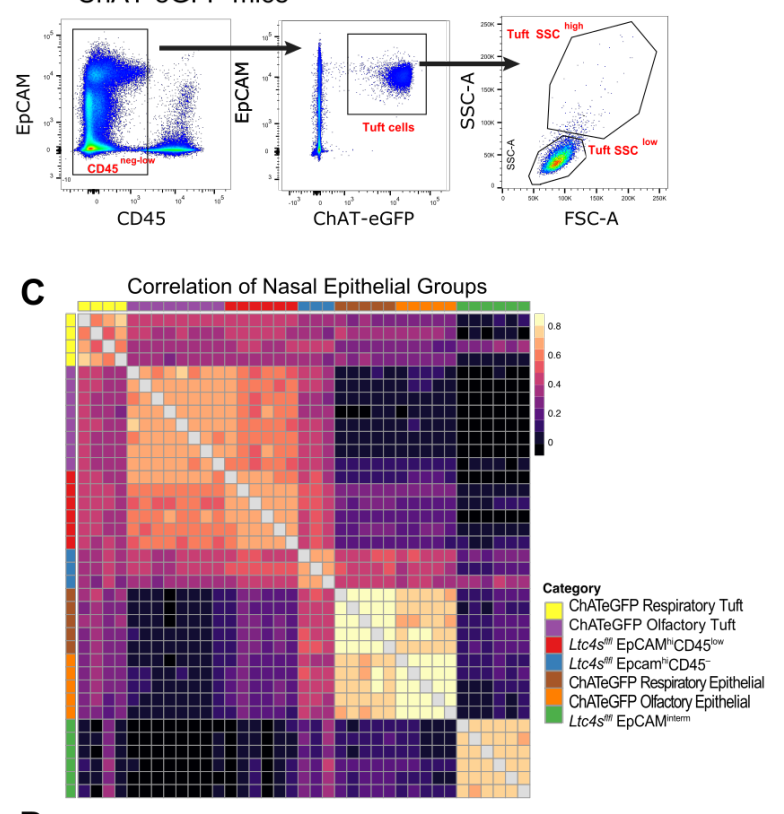

D

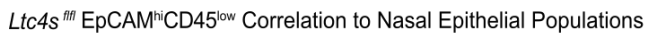

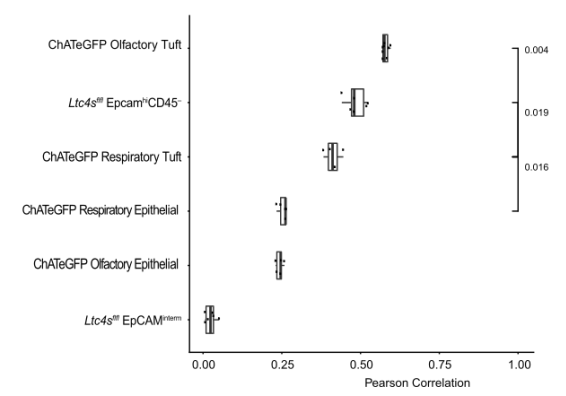

Fig. S3. EpCAM ${ }^{\text {high }}$ CD45 ${ }^{\text {low }}$ cells are highly enriched for tuft cells. (A) Gating strategy for isolation of tuft cells from $L t c 4 s^{f l f l}$ mice. Three populations of $\mathrm{EpCAM}^{+}$cells were distinguished - EpCAM ${ }^{\text {high }}-\mathrm{CD}_{4} 5^{+}, \mathrm{EpCAM}^{\text {high }}-\mathrm{CD} 45^{-}$and EpCAM ${ }^{\text {interm }}$. (B) Gating strategy for isolation of tuft cells from ChAT-eGFP mice. Tuft cells were defined as low or negative for CD45 and high for EpCAM. Olfactory tuft cells were defined as $\mathrm{ChAT}_{-} \mathrm{eGFP}^{+}$cells from the olfactory mucosa with low FSC and SSC. Respiratory tuft cells were defined as tuft cells derived from the respiratory mucosa that were high for FSC and SSC. (C) Heatmap shows Pearson's correlation coefficient across expression levels of all highly variable genes (Methods) between all pairs of samples from nasal epithelial groups from ChAT-eGFP and $L t c 4 s^{f l f l}$ mice, samples are ordered by cluster assignment (color legend). (D) Pearson's correlation coefficient (x-axis) between $L t c 4 s^{f l f l} \mathrm{EpCAM}^{\text {high }} \mathrm{CD} 45^{\text {low }}$ tuft cell-enriched samples (points) and populations of pure tuft cells from ChAT-eGFP mice and other epithelial populations. Boxplots show the median correlation and interquartile range. P-values calculated using Mann-Whitney U-test. 
bioRxiv preprint doi: https://doi.org/10.1101/2021.09.26.461888; this version posted November 10, 2021. The copyright holder for this preprint (which was not certified by peer review) is the author/funder. All rights reserved. No reuse allowed without permission.

A MOUSE BRAIN AND SENSORY NEURONS Chat Ltc4s Both

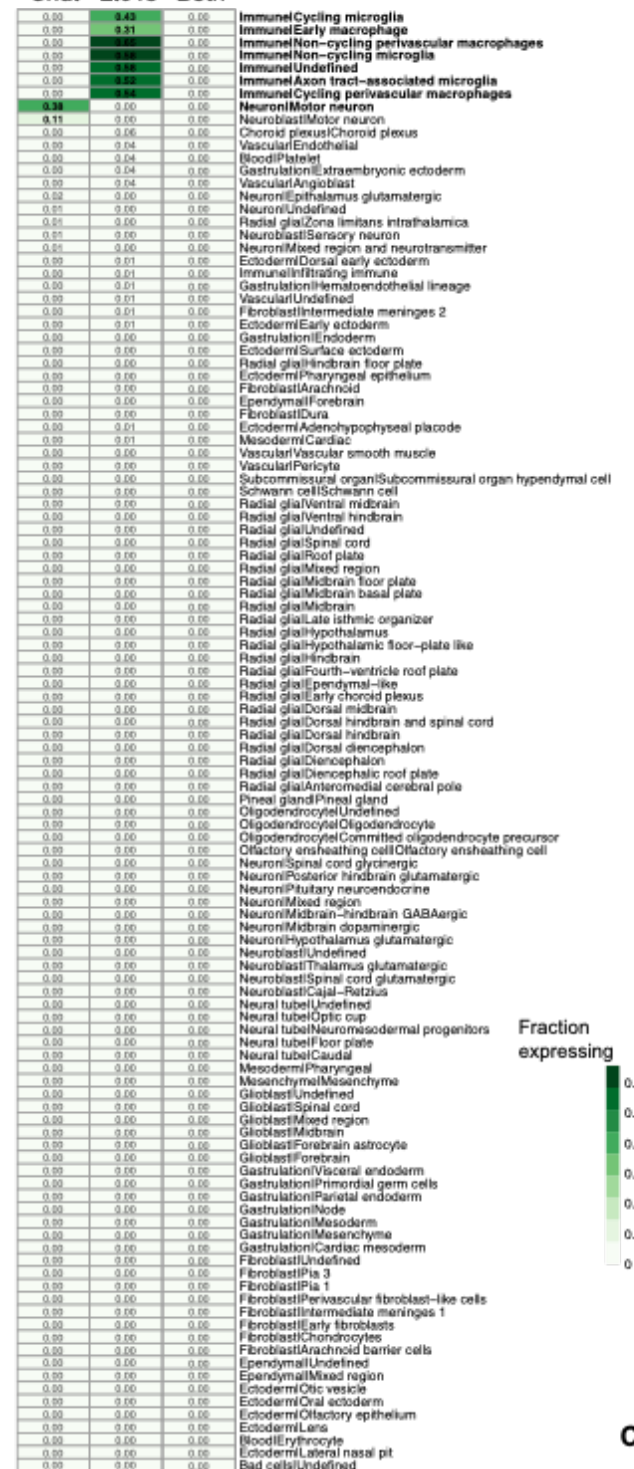

B NASAL MUCOSA

Chat Ltc4s Both

\begin{tabular}{|l|l|l|l|l|l|l|l|l}
\hline 0.76 & 1.00 & 0.76 & hin-sce
\end{tabular}

\begin{tabular}{|l|l|l|l|l|}
\hline 0.00 & 0.54 & 0.00 & Eoshoophe \\
\hline 0.18 & 1.00 & 0.18 & The - Gland \\
\hline
\end{tabular}

\begin{tabular}{l|l|l|l|l|l|l|l}
\hline 0.42 & 0.85 & 0.36 & hin-Mve
\end{tabular}

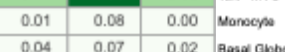

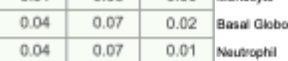

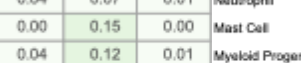

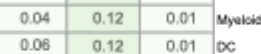

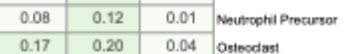

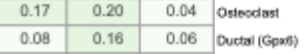

\begin{tabular}{|l|l|l|l|l|l}
\hline 0.07 & 0.13 & 0.05 & OBPE \\
\hline
\end{tabular}

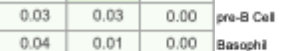

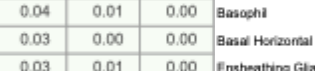

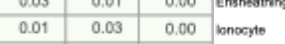

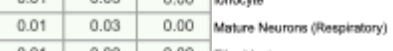

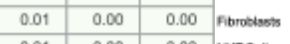

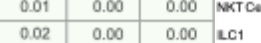

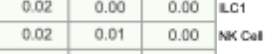

\begin{tabular}{|l|l|l|l|l|l|l}
\hline 0.02 & 0.00 & 0.00 & cos: T eal
\end{tabular}

\begin{tabular}{|l|l|l|l|}
\hline 0.01 & 0.02 & 0.00 & Ductal \\
\hline 0.01 & 0.02 & 0.01 & Seros \\
\hline 0.01 & 0.01 & 0.00 & \\
\hline
\end{tabular}

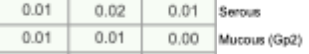

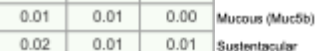

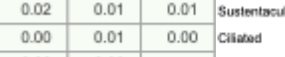

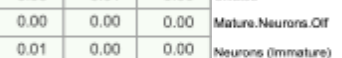

\begin{tabular}{|l|l|l|l|l|}
\hline 0.01 & 0.00 & 0.00 & Newoess \\
\hline 0.17 & 0.00 & 0.00 & LC2 \\
\hline
\end{tabular}

\begin{tabular}{|l|l|l|l|l|l|l|l|l|l|}
\hline 0.11 & 0.06 & 0.00 & $00 \mathrm{C}$ \\
\hline 0.09 & 0.00 & 0.00 & \\
\hline
\end{tabular}

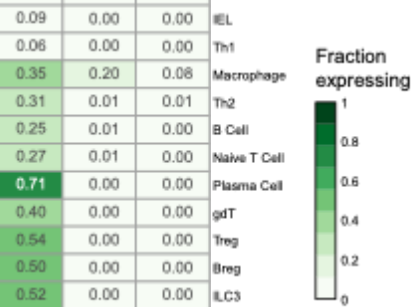

C NASAL MUCOSA

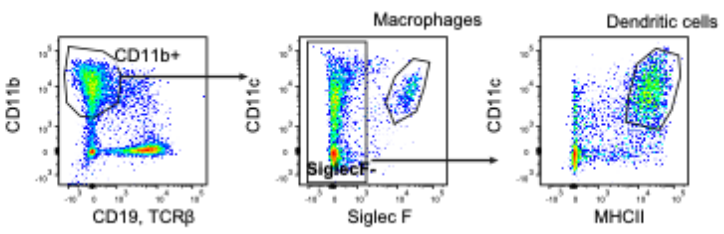

D NASAL MUCOSA

Dendritic Cells

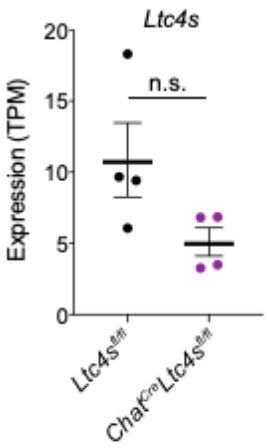


Fig. S4. Chat and Ltc4s are specifically co-expressed in tuft cells. (A) Fraction of cells expressing Chat (first column), Ltc $4 s$ (second column) and both transcripts (third column) in central and peripheral neurons and nervous system immune cells from previously published data downloaded from the Mouse Brain Atlas (36). (B) Fraction of cells expressing Chat (first column), Ltc4s (second column) and both transcripts (third column). Data derived from a newly generated unpublished dataset in our lab of 50, 000 nasal epithelial and immune cells. (C) DCs and macrophages were defined within the $\mathrm{CD}_{4} 5^{+}$cell subset as $\mathrm{CD}_{1}{ }^{-}$(B cell marker), $\mathrm{TCR} \beta^{-}$

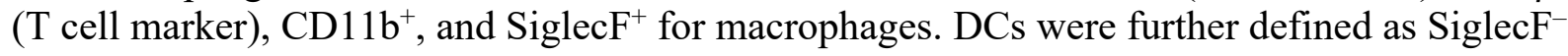
$\mathrm{CD} 11 \mathrm{c}^{+}$and $\mathrm{MHCII}^{+}$. (D) Expression level in transcripts per million (TPM) of Ltc $4 s$ in DCs derived from $L t c 4 s^{f l f l}$ and $C h a t^{C r e} L t c 4 s^{f l f l}$ mice, p adjusted value derived from DeSeq2 analysis, n.s.- not significant. 

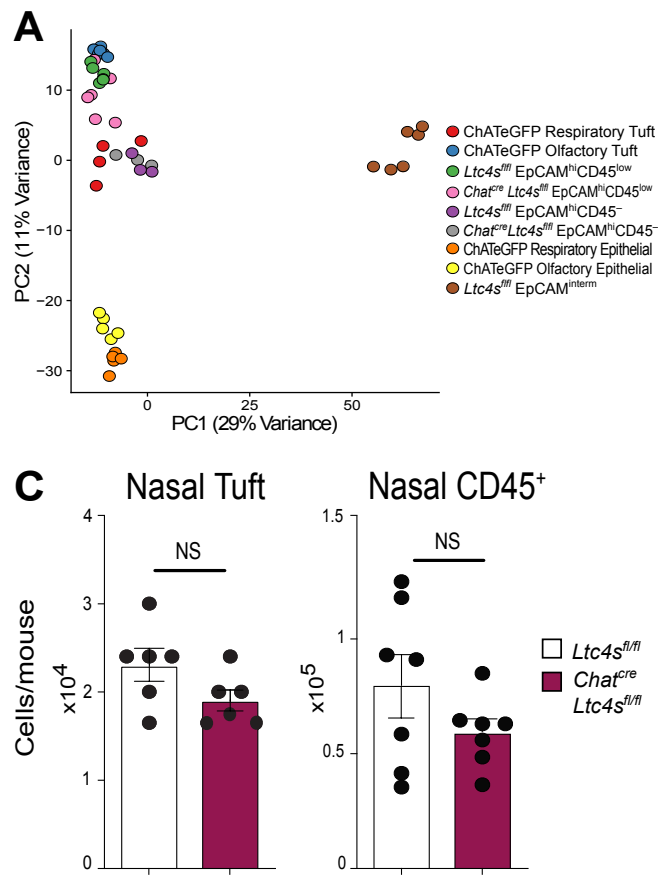

B Correlation of Nasal Epithelial Groups
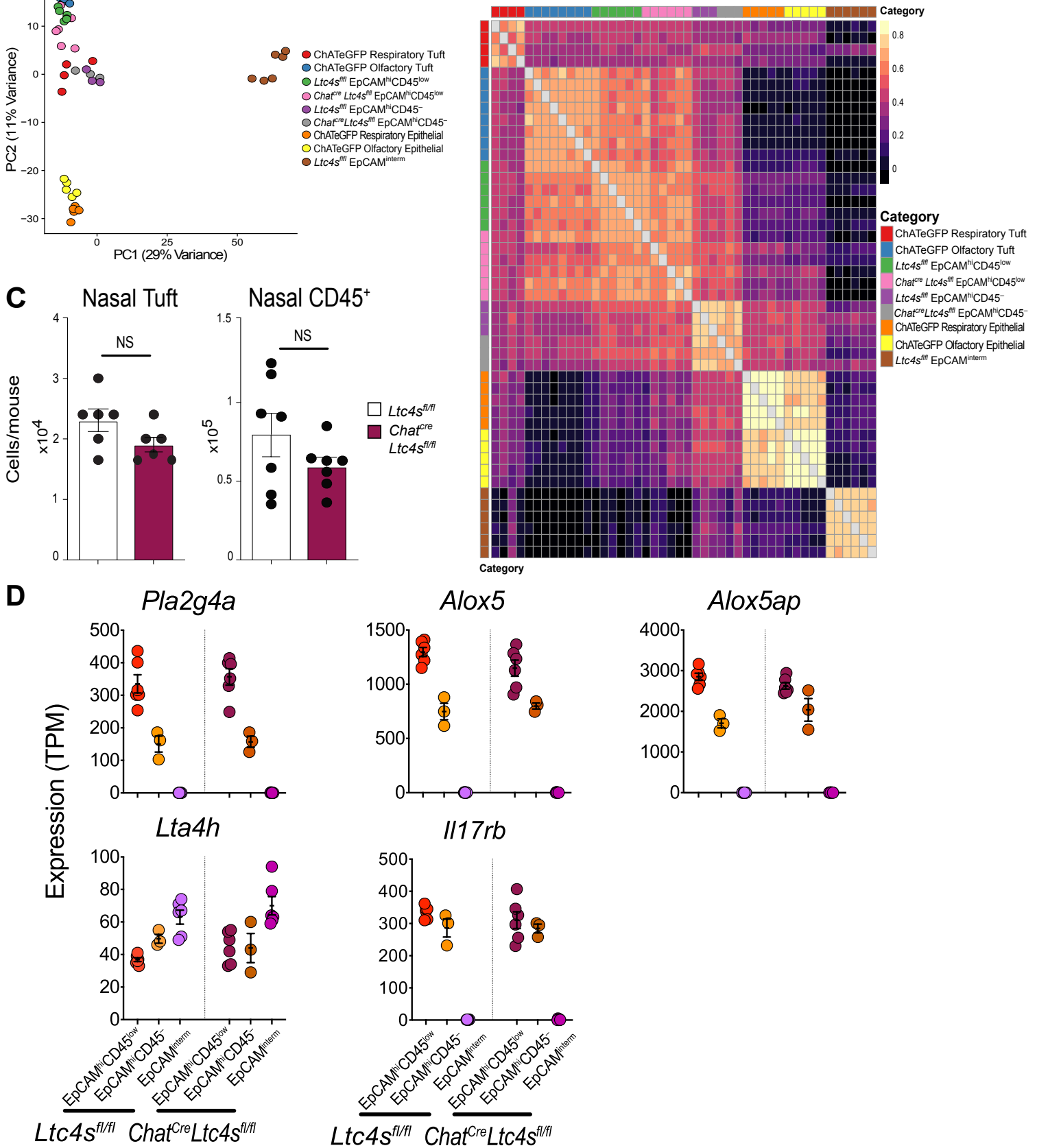

$117 r b$

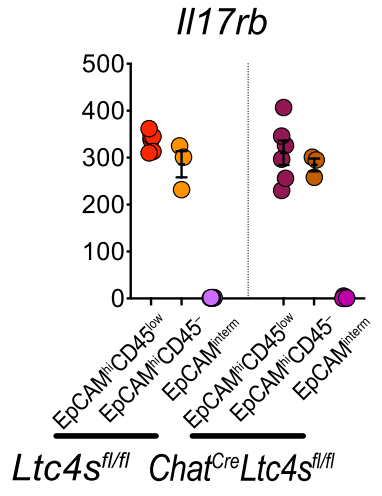

Fig. S5. The transcriptional profile of tuft cells from Chat ${ }^{C r e} L t c 4 s^{f l f l}$ mice is unaltered. (A) Principal component analysis of tuft cells from ChAT-eGFP mice and tuft cells enriched and not enriched populations of epithelial cells derived from the nasal mucosa of ChAT-eGPF mice, $L t c 4 s^{f l f l}$ and $C h a t^{C r e} L t c 4 s^{f l f l}$ mice. Numbers indicate frequency of transcripts described by each principal component. (B) Pearson correlation coefficient $(r)$ between the nasal epithelial groups from ChAT-eGFP, $L t c 4 s^{f l f l}$ and $C h a t^{C r e} L t c 4 s^{f l f l}$ mice ordered by cluster assignment. (C) Numbers of nasal tuft cells (EpCAM ${ }^{\text {high }} \mathrm{CD} 45^{\text {low }} \mathrm{SSC}^{\text {low }}$ ) and nasal CD $45^{+}$cells in $L t c 4 S^{f l f l}$ and Chat ${ }^{C r e} L t c 4 s^{f l f l}$ mice derived from cell sorting. NS = not significant.(D) Expression level in transcripts per million (TPM) of the indicated genes in epithelial cell subsets from $L t c 4 s^{f l f l}$ and Chat ${ }^{\text {Cre }} L t c 4 s^{\text {flflf }}$ mice. 

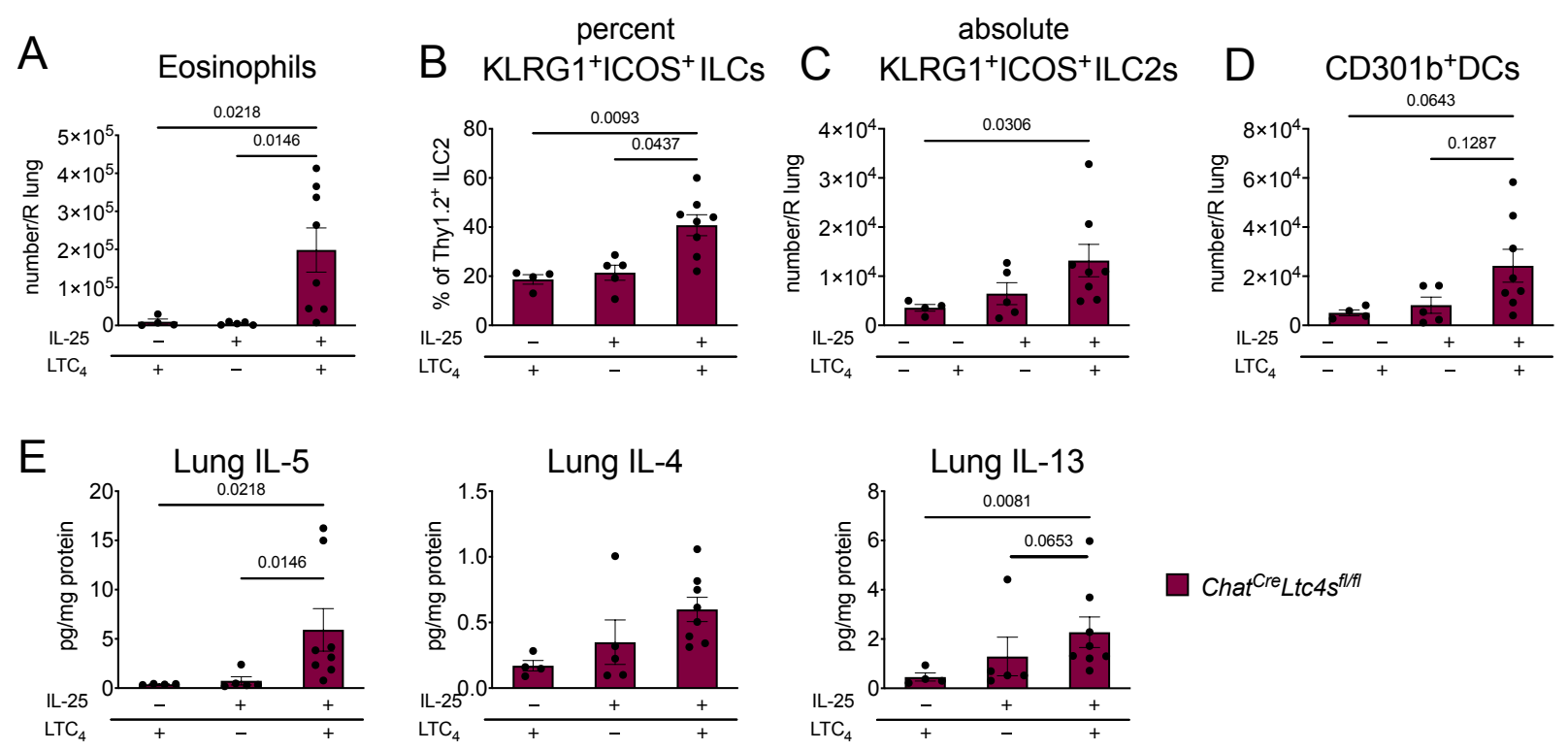

Fig. S6. The synergy of IL-25 and LTC4 is preserved in $\mathrm{Chat}^{C r e} \mathrm{Ltc}_{\mathrm{s}} \mathrm{s}^{\mathrm{fl} / f l}$ mice. Chat ${ }^{C r e} L t c 4 \mathrm{~s}^{f l / f l}$ mice were given $\mathrm{LTC}_{4}(1.6 \mathrm{mmol})$ ' or IL-25 (100 ng) or a combination of LTC 4 and IL-25 and assessed 2 days after the last dose. The frequency of eosinophils (a), frequency and number of $\mathrm{KLRG}^{+} \mathrm{ICOS}^{+} \mathrm{Thy} 1.2^{+} \mathrm{ILC} 2 \mathrm{~s}(\mathbf{B}, \mathbf{C})$, and number of CD301 ${ }^{+} \mathrm{MHCII}^{+} \mathrm{CD} 11 \mathrm{~b}^{+} \mathrm{DCs}(\mathbf{D})$ were assessed by FACS. (E). Lung cytokine protein concentration was determined by LegendPlex. Data are means \pm SEM pooled from 3 independent experiments, each dot is a mouse, $p$ values $<0.05$ indicated, Kruskal-Wallis ANOVA with Dunn's correction for multiple comparisons.
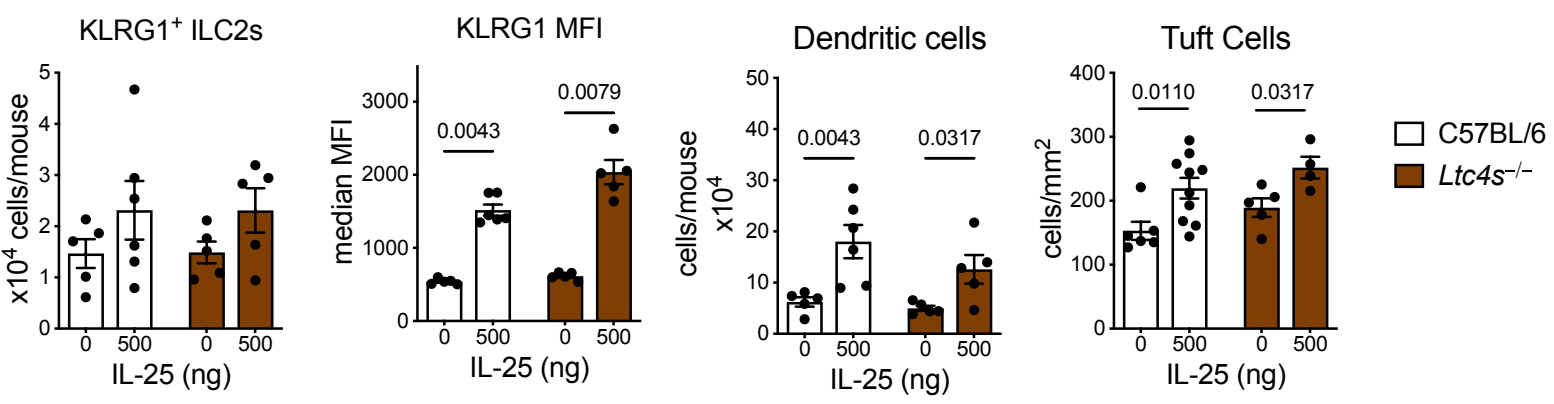

Fig. S7. High dose IL-25 induced inflammation is preserved in $\mathrm{Ltc}_{\mathbf{S}} \mathrm{s}^{-/}$mice. WT and $L t c 4 s^{-/-}$mice were given 3 daily intranasal doses of $500 \mathrm{ng}$ of IL-25 and assessed 2 days after the last dose. Lung KLRG1 ${ }^{+}$ILC2 numbers and KLRG1 MFI and DCs were assessed in the lung and tuft cells in the trachea 48 hours after the last IL-25 inhalation. Data are means + SEM from $\geq 2$ experiments; each circle represents a separate mouse, Mann Whitney $U$ test, $p$ values $<0.05$ are indicated. 
TABLE 1

Name of Material/ Equipment

Company

Catalog Number

Reagents

\begin{tabular}{|c|c|c|}
\hline REAGENT or RESOURCE & SOURCE & IDENTIFIER \\
\hline \multicolumn{3}{|l|}{ Antibodies } \\
\hline $\begin{array}{l}\text { Anti mouse/human DCLK1 (Polyclonal } \\
\text { Rabbit Ig) }\end{array}$ & Abcam & cat\# ab31704 \\
\hline Normal Donkey Serum & $\begin{array}{l}\text { Jackson } \\
\text { ImmunoResearch }\end{array}$ & cat\# 017-000-121 \\
\hline $\begin{array}{l}\text { donkey anti-rabbit IgG }(\mathrm{H}+\mathrm{L}) \text { Highly } \\
\text { Cross-Adsorbed Secondary Antibody, } \\
\text { Alexa Fluor } 594\end{array}$ & $\begin{array}{l}\text { Life } \\
\text { Technologies/Molecular } \\
\text { Probes }\end{array}$ & cat\#A-21207 \\
\hline Trustain FC Block & Biolegend & cat\# 101320 \\
\hline APC anti-mouse CD326 (EpCAM) & Biolegend & cat\#118214 \\
\hline Brilliant Violet 421 anti-mouse CD45 & Biolegend & cat $\# 103134$ \\
\hline FITC anti-mouse I-A/I-E & Biolegend & cat\#107606 \\
\hline Brilliant Violet 421 anti-mouse CD8a & Biolegend & cat\#100748 \\
\hline APC/Cy7 anti-mouse/human CD11b & Biolegend & cat\#101226 \\
\hline FITC anti-mouse FceRI $\alpha$ & Biolegend & cat\#134306 \\
\hline FITC anti-mouse CD11c & Biolegend & cat\#117306 \\
\hline PerCP/Cy5.5 anti-mouse Siglec F & BD Biosciences & cat\# 565526 \\
\hline FITC Rat anti-mouse IgE & BD Biosciences & cat\#553415 \\
\hline
\end{tabular}

\begin{tabular}{|c|c|c|}
\hline \multicolumn{3}{|l|}{$\begin{array}{l}\text { Chemicals, Peptides, and Recombinant } \\
\text { Proteins }\end{array}$} \\
\hline $\begin{array}{l}\text { Alternaria alternata culture filtrate (lot\# } \\
\text { 151774) }\end{array}$ & Greer Laboratories & cat\#XPM1C3A25 \\
\hline Hoechst 33342 & Sigma & cat\#14533 \\
\hline DNAse I & Sigma & cat\# 10104159001 \\
\hline Dispase & Gibco & cat\# 17105041 \\
\hline $\begin{array}{l}\text { HEPES-Tyrode's Buffer Without } \\
\text { Calcium }\end{array}$ & Boston BioProducts & cat\# PY-912 \\
\hline Tyrode's Solution (HEPES-Buffered) & Boston BioProducts & cat\# BSS-355 \\
\hline
\end{tabular}




\begin{tabular}{|c|c|c|}
\hline L-Cysteine & Sigma & cat\# C7352 \\
\hline Papain from papaya latex & Sigma & cat\# P3125 \\
\hline Leupeptin trifluoroacetate salt & Sigma & cat\# L2023 \\
\hline Propidium iodide & Sigma & cat\# P4170 \\
\hline A23187 & Cayman & cat\# 11016 \\
\hline ATP- $\gamma-\mathrm{S}$ & Abcam & cat\# ab138911 \\
\hline 2-Mercaptoethanol & Gibco & cat\#21985023 \\
\hline Cysteinyl Leukotriene ELISA Kit & Cayman & cat\# 500390 \\
\hline Prostaglandin D2 ELISA Kit & Cayman & cat\# 512031 \\
\hline $\begin{array}{l}\text { Target Retrieval Solution } 10 \mathrm{x} \\
\text { Concentrate }\end{array}$ & Dako & cat\# S1699 \\
\hline Leukotriene C4 & Cayman Chemical & cat\#20210 \\
\hline N-methyl Leukotriene C4 & Cayman Chemical & cat\#13390 \\
\hline Recombinant mouse IL17PE/IL-25 & R\&D systems & cat\#7909-IL/CF \\
\hline $\begin{array}{l}\text { LEGENDplex }{ }^{\mathrm{TM}} \text { MU Th Cytokine } \\
\text { Panel (12-plex) w/ VbP V03 }\end{array}$ & Biolegend & cat\#741044 \\
\hline $\begin{array}{l}\text { Pierce T-PERTM, Tissue Protein } \\
\text { Extraction Reagent }\end{array}$ & ThermoFisher & cat\#78510 \\
\hline $\begin{array}{l}\text { Roche cOmplete }{ }^{\mathrm{TM}} \text { Protease Inhibitor } \\
\text { Cocktail }\end{array}$ & Sigma Aldrich & cat\#4693116001 \\
\hline BCA assay & ThermoFisher & cat\# 23225 \\
\hline TCL buffer & Qiagen & cat\# 1031576 \\
\hline$\beta$-mercaptoethanol & Sigma & cat \#M6250 \\
\hline
\end{tabular}

Media
\begin{tabular}{|l|l|l|}
\hline DMEM/F-12 & ThermoFischer & cat\#11320033 \\
\hline HEPES & ThermoFischer & cat\#AAJ1692622 \\
\hline Penicillin-Streptomycin & ThermoFischer & cat\#15140148 \\
\hline Fetal Bovine Serum & ThermoFischer & cat\#10082139 \\
\hline Nu-serum & Corning & cat\#355100 \\
\hline L-glutamin & & \\
\hline BSA & ThermoFischer & cat\#BP9706100 \\
\hline & & \\
Amphotericin B & Gibco & cat\#1529001 \\
\hline RPMI & Corning & cat\#10040CV \\
\hline
\end{tabular}




\begin{tabular}{|c|c|c|}
\hline \multicolumn{2}{|l|}{$\begin{array}{l}\text { Experimental Models: } \\
\text { Organisms/Strains } \\
\end{array}$} & \multirow[b]{2}{*}{27} \\
\hline C57BL/6 Mouse & Charles River & \\
\hline$L t c 4 s^{-/-}$ & Dr. Yoshihide Kanaoka & \\
\hline $\begin{array}{l}C h A T^{B A C}-e G F P(B 6 . C g-T g(R P 23- \\
268 L 19-E G F P) 2 M i k / J)\end{array}$ & The Jackson Laboratory & 7902 \\
\hline $\begin{array}{l}\text { ChAT-IRES-Cre::frt-neo-frt } \\
\left(\text { Chat }^{\text {tm2(cre)Lowl }) / J}\right.\end{array}$ & The Jackson Laboratory & 006410 \\
\hline$L t c 4 S^{f l f l}$ & Dr. Joshua Boyce & \\
\hline Mcpt5-Cre & Axel Roers & \\
\hline Cysltr2 $2^{-/-}$ & Dr. Yoshihide Kanaoka & \\
\hline Oxgr1-/- & Dr. Yoshihide Kanaoka & \\
\hline C57BL/6N-Cysltr1tm1 $1^{Y k n / J}$ & The Jackson Laboratory & 30814 \\
\hline Pou2f3-/- & Ichiro Matsumoto & \\
\hline
\end{tabular}

\begin{tabular}{|c|c|c|}
\hline \multicolumn{3}{|c|}{ Software and Algorithms } \\
\hline FlowJo v.8 & FlowJo, LLC & $\begin{array}{r}\text { https://www.www.flo } \\
\text { wjo.com }\end{array}$ \\
\hline Prism 8 & GraphPad Software & $\begin{array}{l}\text { https://www.graphpad. } \\
\text { com/scientific- } \\
\text { software/prism/ }\end{array}$ \\
\hline $\mathrm{R}$ and $\mathrm{R}$ studio & & $\frac{\text { http://www.r- }}{\text { project.com/ }}$ \\
\hline ImageJ & & $\begin{array}{l}\text { National Institutes of } \\
\text { Health, Bethesda, MD }\end{array}$ \\
\hline
\end{tabular}


bioRxiv preprint doi: https://doi.org/10.1101/2021.09.26.461888; this version posted November 10, 2021. The copyright holder for this preprint (which was not certified by peer review) is the author/funder. All rights reserved. No reuse allowed without permission. 


\section{REFERENCES AND NOTES:}

1. P. G. Fallon et al., Identification of an interleukin (IL)-25-dependent cell population that provides IL-4, IL-5, and IL-13 at the onset of helminth expulsion. The Journal of experimental medicine 203, 1105-1116 (2006).

2. L. A. Monticelli et al., Innate lymphoid cells promote lung-tissue homeostasis after infection with influenza virus. Nature immunology 12, 1045-1054 (2011).

3. B. N. Lambrecht, H. Hammad, Allergens and the airway epithelium response: gateway to allergic sensitization. The Journal of allergy and clinical immunology 134, 499-507 (2014).

4. H. Hammad, B. N. Lambrecht, Barrier Epithelial Cells and the Control of Type 2 Immunity. Immunity 43, 29-40 (2015).

5. J. von Moltke et al., Leukotrienes provide an NFAT-dependent signal that synergizes with IL-33 to activate ILC2s. Journal of Experimental Medicine 214, 27-37 (2017).

6. T. A. Doherty et al., Lung type 2 innate lymphoid cells express cysteinyl leukotriene receptor 1, which regulates TH2 cytokine production. The Journal of allergy and clinical immunology 132, 205-213 (2013).

7. S. J. Lund et al., Leukotriene C4 Potentiates IL-33-Induced Group 2 Innate Lymphoid Cell Activation and Lung Inflammation. Journal of immunology (Baltimore, Md. : 1950) 199, 1096-1104 (2017).

8. S. Talbot et al., Silencing Nociceptor Neurons Reduces Allergic Airway Inflammation. Neuron 87, 341-354 (2015).

9. A. Wallrapp et al., The neuropeptide NMU amplifies ILC2-driven allergic lung inflammation. Nature 549, 351-356 (2017).

10. E. A. Sell, J. F. Ortiz-Carpena, D. R. Herbert, N. A. Cohen, Tuft cells in the pathogenesis of chronic rhinosinusitis with nasal polyps and asthma. Ann Allergy Asthma Immunol 126, 143-151 (2021).

11. D. T. Montoro et al., A revised airway epithelial hierarchy includes CFTR-expressing ionocytes. Nature 560, 319-324 (2018).

12. T. E. Finger et al., Solitary chemoreceptor cells in the nasal cavity serve as sentinels of respiration. Proceedings of the National Academy of Sciences of the United States of America 100, 8981-8986 (2003).

13. M. Tizzano, M. Cristofoletti, A. Sbarbati, T. E. Finger, Expression of taste receptors in solitary chemosensory cells of rodent airways. BMC pulmonary medicine 11, 3 (2011).

14. G. Krasteva et al., Cholinergic chemosensory cells in the trachea regulate breathing. Proceedings of the National Academy of Sciences of the United States of America 108, 9478-9483 (2011).

15. A. Hansen, T. E. Finger, Is TrpM5 a reliable marker for chemosensory cells? Multiple types of microvillous cells in the main olfactory epithelium of mice. BMC Neurosci 9 , 115 (2008).

16. S. Ualiyeva et al., Airway brush cells generate cysteinyl leukotrienes through the ATP sensor P2Y2. Sci Immunol 5, (2020).

17. M. Ohmoto et al., Pou2f3/Skn-1a is necessary for the generation or differentiation of solitary chemosensory cells in the anterior nasal cavity. Biosci Biotechnol Biochem 77, 2154-2156 (2013).

18. T. Yamaguchi et al., Skn-1a/Pou2f3 is required for the generation of Trpm5-expressing microvillous cells in the mouse main olfactory epithelium. BMC Neurosci 15, 13 (2014). 
19. W. Lin, E. A. Ezekwe, Jr., Z. Zhao, E. R. Liman, D. Restrepo, TRPM5-expressing microvillous cells in the main olfactory epithelium. BMC Neurosci 9, 114 (2008).

20. L. G. Bankova et al., The cysteinyl leukotriene 3 receptor regulates expansion of IL-25producing airway brush cells leading to type 2 inflammation. Science Immunology $\mathbf{3}$, (2018).

21. J. von Moltke, M. Ji, H. E. Liang, R. M. Locksley, Tuft-cell-derived IL-25 regulates an intestinal ILC2-epithelial response circuit. Nature 529, 221-225 (2016).

22. J. Yamashita, M. Ohmoto, T. Yamaguchi, I. Matsumoto, J. Hirota, Skn-1a/Pou2f3 functions as a master regulator to generate Trpm5-expressing chemosensory cells in mice. PloS one 12, e0189340 (2017).

23. M. S. Nadjsombati et al., Detection of Succinate by Intestinal Tuft Cells Triggers a Type 2 Innate Immune Circuit. Immunity 49, 33-41 e37 (2018).

24. A. L. Haber et al., A single-cell survey of the small intestinal epithelium. Nature 551, 333-339 (2017).

25. T. Yoshimoto, R. J. Soberman, B. Spur, K. F. Austen, Properties of highly purified leukotriene C4 synthase of guinea pig lung. The Journal of clinical investigation 81, 866871 (1988).

26. L. G. Bankova, J. A. Boyce, A new spin on mast cells and cysteinyl leukotrienes: Leukotriene E4 activates mast cells in vivo. The Journal of allergy and clinical immunology 142, 1056-1057 (2018).

27. K. R. Lynch et al., Characterization of the human cysteinyl leukotriene CysLT1 receptor. Nature 399, 789-793 (1999).

28. C. E. Heise et al., Characterization of the human cysteinyl leukotriene 2 receptor. The Journal of biological chemistry 275, 30531-30536 (2000).

29. Y. Kanaoka, A. Maekawa, K. F. Austen, Identification of GPR99 protein as a potential third cysteinyl leukotriene receptor with a preference for leukotriene E4 ligand. The Journal of biological chemistry 288, 10967-10972 (2013).

30. T. Liu et al., Type 2 Cysteinyl Leukotriene Receptors Drive IL-33-Dependent Type 2 Immunopathology and Aspirin Sensitivity. Journal of immunology (Baltimore, Md. : 1950) 200, 915-927 (2018).

31. T. Liu, T. M. Laidlaw, H. R. Katz, J. A. Boyce, Prostaglandin E2 deficiency causes a phenotype of aspirin sensitivity that depends on platelets and cysteinyl leukotrienes. Proceedings of the National Academy of Sciences of the United States of America 110, 16987-16992 (2013).

32. J. W. McGinty et al., Tuft-Cell-Derived Leukotrienes Drive Rapid Anti-helminth Immunity in the Small Intestine but Are Dispensable for Anti-protist Immunity. Immunity 52, 528-541 e527 (2020).

33. F. Gerbe et al., Intestinal epithelial tuft cells initiate type 2 mucosal immunity to helminth parasites. Nature 529, 226-230 (2016).

34. Y. Huang et al., IL-25-responsive, lineage-negative KLRG1(hi) cells are multipotential 'inflammatory' type 2 innate lymphoid cells. Nature immunology 16, 161-169 (2015).

35. A. Zeisel et al., Brain structure. Cell types in the mouse cortex and hippocampus revealed by single-cell RNA-seq. Science 347, 1138-1142 (2015).

36. A. Zeisel et al., Molecular Architecture of the Mouse Nervous System. Cell 174, 9991014 e1022 (2018). 
37. M. A. Cox et al., Choline acetyltransferase-expressing T cells are required to control chronic viral infection. Science 363, 639-644 (2019).

38. L. B. Roberts et al., Acetylcholine production by group 2 innate lymphoid cells promotes mucosal immunity to helminths. Sci Immunol 6, (2021).

39. C. Chu et al., The ChAT-acetylcholine pathway promotes group 2 innate lymphoid cell responses and anti-helminth immunity. Sci Immunol 6, (2021).

40. N. A. Barrett, A. Maekawa, O. M. Rahman, K. F. Austen, Y. Kanaoka, Dectin-2 recognition of house dust mite triggers cysteinyl leukotriene generation by dendritic cells. Journal of immunology (Baltimore, Md. : 1950) 182, 1119-1128 (2009).

41. D. J. Figueroa et al., Expression of cysteinyl leukotriene synthetic and signalling proteins in inflammatory cells in active seasonal allergic rhinitis. Clinical and experimental allergy : journal of the British Society for Allergy and Clinical Immunology 33, 13801388 (2003).

42. D. Tworek et al., IL-25 Receptor Expression on Airway Dendritic Cells after Allergen Challenge in Subjects with Asthma. American journal of respiratory and critical care medicine 193, 957-964 (2016).

43. L. G. Bankova et al., Leukotriene E4 elicits respiratory epithelial cell mucin release through the G-protein-coupled receptor, GPR99. Proceedings of the National Academy of Sciences of the United States of America 113, 6242-6247 (2016).

44. M. F. DiMaio, M. Kattan, D. Ciurea, J. Gil, R. Dische, Brush cells in the human fetal trachea. Pediatric pulmonology 8, 40-44 (1990).

45. B. D. Gulbransen, T. R. Clapp, T. E. Finger, S. C. Kinnamon, Nasal solitary chemoreceptor cell responses to bitter and trigeminal stimulants in vitro. J Neurophysiol 99, 2929-2937 (2008).

46. G. Krasteva, B. J. Canning, T. Papadakis, W. Kummer, Cholinergic brush cells in the trachea mediate respiratory responses to quorum sensing molecules. Life Sci 91, 992-996 (2012).

47. M. Tizzano et al., Nasal chemosensory cells use bitter taste signaling to detect irritants and bacterial signals. Proceedings of the National Academy of Sciences of the United States of America 107, 3210-3215 (2010).

48. A. Perniss et al., Chemosensory Cell-Derived Acetylcholine Drives Tracheal Mucociliary Clearance in Response to Virulence-Associated Formyl Peptides. Immunity 52, 683-699 e611 (2020).

49. Z. Fu, T. Ogura, W. Luo, W. Lin, ATP and Odor Mixture Activate TRPM5-Expressing Microvillous Cells and Potentially Induce Acetylcholine Release to Enhance Supporting Cell Endocytosis in Mouse Main Olfactory Epithelium. Front Cell Neurosci 12, 71 (2018).

50. R. J. Lee et al., Bitter and sweet taste receptors regulate human upper respiratory innate immunity. The Journal of clinical investigation 124, 1393-1405 (2014).

51. T. A. Doherty et al., STAT6 regulates natural helper cell proliferation during lung inflammation initiated by Alternaria. American journal of physiology. Lung cellular and molecular physiology 303, L577-588 (2012).

52. T. M. Laidlaw, J. A. Boyce, Cysteinyl leukotriene receptors, old and new; implications for asthma. Clinical and experimental allergy : journal of the British Society for Allergy and Clinical Immunology 42, 1313-1320 (2012). 
53. N. A. Barrett et al., Dectin-2 mediates Th2 immunity through the generation of cysteinyl leukotrienes. The Journal of experimental medicine 208, 593-604 (2011).

54. M. W. Parsons et al., Dectin-2 regulates the effector phase of house dust mite-elicited pulmonary inflammation independently from its role in sensitization. Journal of immunology (Baltimore, Md. : 1950) 192, 1361-1371 (2014).

55. T. Liu et al., Aspirin-Exacerbated Respiratory Disease Involves a Cysteinyl LeukotrieneDriven IL-33-Mediated Mast Cell Activation Pathway. Journal of immunology (Baltimore, Md. : 1950), (2015).

56. N. A. Barrett et al., Cysteinyl leukotriene 2 receptor on dendritic cells negatively regulates ligand-dependent allergic pulmonary inflammation. Journal of immunology (Baltimore, Md. : 1950) 189, 4556-4565 (2012).

57. H. E. Cummings et al., Cutting edge: Leukotriene $\mathrm{C} 4$ activates mouse platelets in plasma exclusively through the type 2 cysteinyl leukotriene receptor. Journal of immunology (Baltimore, Md. : 1950) 191, 5807-5810 (2013).

58. M. K. Oyoshi et al., Eosinophil-derived leukotriene C4 signals via type 2 cysteinyl leukotriene receptor to promote skin fibrosis in a mouse model of atopic dermatitis. Proceedings of the National Academy of Sciences of the United States of America 109, 4992-4997 (2012).

59. C. K. Rane et al., Development of solitary chemosensory cells in the distal lung after severe influenza injury. American journal of physiology. Lung cellular and molecular physiology 316, L1141-L1149 (2019).

60. L. Da Dalt et al., Nasal lavage leukotrienes in infants with RSV bronchiolitis. Pediatric allergy and immunology : official publication of the European Society of Pediatric Allergy and Immunology 18, 100-104 (2007).

61. K. Oymar, T. Halvorsen, L. Aksnes, Mast cell activation and leukotriene secretion in wheezing infants. Relation to respiratory syncytial virus and outcome. Pediatric allergy and immunology : official publication of the European Society of Pediatric Allergy and Immunology 17, 37-42 (2006).

62. G. Piedimonte et al., Leukotriene synthesis during respiratory syncytial virus bronchiolitis: influence of age and atopy. Pediatric pulmonology 40, 285-291 (2005).

63. J. Beale et al., Rhinovirus-induced IL-25 in asthma exacerbation drives type 2 immunity and allergic pulmonary inflammation. Science translational medicine 6, 256ra134 (2014).

64. Y. Kanaoka, A. Maekawa, J. F. Penrose, K. F. Austen, B. K. Lam, Attenuated zymosaninduced peritoneal vascular permeability and IgE-dependent passive cutaneous anaphylaxis in mice lacking leukotriene $\mathrm{C} 4$ synthase. The Journal of biological chemistry 276, 22608-22613 (2001).

65. T. C. Beller, A. Maekawa, D. S. Friend, K. F. Austen, Y. Kanaoka, Targeted gene disruption reveals the role of the cysteinyl leukotriene 2 receptor in increased vascular permeability and in bleomycin-induced pulmonary fibrosis in mice. The Journal of biological chemistry 279, 46129-46134 (2004).

66. J. Scholten et al., Mast cell-specific Cre/loxP-mediated recombination in vivo. Transgenic research 17, 307-315 (2008).

67. I. Matsumoto, M. Ohmoto, M. Narukawa, Y. Yoshihara, K. Abe, Skn-1a (Pou2f3) specifies taste receptor cell lineage. Nat Neurosci 14, 685-687 (2011).

68. S. Ualiyeva, E. Yoshimoto, N. A. Barrett, L. G. Bankova, Isolation and Quantitative Evaluation of Brush Cells from Mouse Tracheas. J Vis Exp 59496, (2019). 
FUNDING: This work was supported by:

National Institutes of Health grant K08 AI132723 (LGB)

National Institutes of Health grant 1R21AI154345 (LGB and ALH)

National Institutes of Health grant R01AI078908

National Institutes of Health grant R37AI052353 (JAB)

R01AI136041 (JAB)

R01HL136209 (JAB)

National Institutes of Health grant R01 AI134989 (NAB)

U19 AI095219 (NAB, JAB)

AAAAI Foundation Faculty Development Award (LGB)

Joycelyn C. Austen Fund for Career Development of Women Physician Scientists (LGB)

generous donation by the Vinik family (LGB)

\section{Author contributions:}

Conceptualization: LGB, ALH and JAB

Methodology: LGB, ALH, EL, SU

Investigation: LGB, SU, AAB, CW, EL, JL

Writing: LGB, AHL, JAB, NAB, IM

Funding Acquisition: LGB, JAB, NAB, AHL

Resources: TL, IM and JAB

\section{Competing interests:}

The authors declare that they have no competing interests. 
Acknowledgements: We thank Adam Chicoine from Brigham and Women's Hospital Human Immunology Center Flow Core for his help with FACS sorting. We are grateful to Charles Vidoudez and Sunia Trauger from the Harvard Center for Mass Spectrometry and Oswald Quehenberger from the University of California San Diego Lipidomics Core for their expertise and help setting up the mass spectrometry assays for CysLTs and lipidomics assays. We are also thankful to Lisa Goodrich at the Department of Neurobiology at Harvard Medical School for providing reagents and infrastructure for in situ hybridization. Schematic diagrams were created using BioRender. 
bioRxiv preprint doi: https://doi.org/10.1101/2021.09.26.461888; this version posted November 10, 2021. The copyright holder for this preprint (which was not certified by peer review) is the author/funder. All rights reserved. No reuse allowed without permission. 
bioRxiv preprint doi: https://doi.org/10.1101/2021.09.26.461888; this version posted November 10, 2021. The copyright holder for this preprint (which was not certified by peer review) is the author/funder. All rights reserved. No reuse allowed without permission. 